\title{
O potencial simbiótico da análise schenkeriana na performance e análise musical do Praeambulum da Partita n. 5 para teclas, de J. S. Bach
}

\author{
Renata Coutinho de Barros Correia \\ Universidade de São Paulo \\ renatacoutinhobarros@gmail.com \\ Jéssica Evelyn Papi Silva \\ Universidade Estadual Paulista \\ jessi.papi@gmail.com
}

\begin{abstract}
Resumo: $\mathrm{O}$ artigo trata sobre o potencial da ferramenta de análise schenkeriana na abordagem de questões performáticas. Ilustra o papel desta proposta na produção de metáforas expressivas (projeção sonora e modelagem afetiva), bem como demonstra a possibilidade de contribuição mútua ou "processo simbiótico" entre a análise e a performance musical. Tem como objeto o Praeambulum da Partita n. 5, de J. S. Bach, selecionado em função de seus desafios interpretativos. A análise de vozes condutoras é considerada num contexto analítico abrangente, sendo complementada pela observação de eventos métricos e a análise de elementos expressivos advindos de gravações (dinâmica, articulação e agógica), que é apoiada no emprego do software Sonic Visualiser. Os resultados mostram como noções advindas da teoria analítica de Schenker tendem a contribuir ao embasamento de decisões de realização por parte do performer, bem como enriquecer o seu processo interpretativo.
\end{abstract}

Palavras-chave: Relação análise-performance, Desafios em performance, Abordagem schenkeriana, Análise da performance.

\section{The symbiotic potential of Schenkerian analysis in the performance and musical analysis of Praeambulum from Partita $n .5$ for harpsichord, by J.S. Bach}

\begin{abstract}
The article approaches the potential of the schenkerian analysis tool in addressing performance issues. It illustrates the employment of this tool in the production of expressive metaphors (sound projection and affective modeling), as well as it demonstrates the possibility of a mutual contribution or "symbiotic process" between analysis and performance. Its object is the Praeambulum of J. S. Bach's Partita n. 5, which was selected due to its interpretative challenges. The analysis of voice leading, which is considered in a comprehensive analytical context, it is complemented by the observation of metric events and analysis of expressive elements from recordings (dynamic, articulation and agogic), supported by the using of the Sonic Visualiser software. The results show how notions arising from Schenker's theory tend to contribute to performance decisions by the performer, as well as its interpretative process.
\end{abstract}

Keywords: Relationship between analysis and musical performance, Challenges in musical performance, Schenkerian approach, Analysis of performance.

O presente artigo desenvolve o trabalho apresentado no V Encontro Internacional de Teoria e Análise Musical, EITAM5 (CORREIA; SILVA, 2019, p. 55-71). 


\section{Considerações preliminares: breve contextualização histórica sobre o desenvolvimento dos estudos em Análise e Performance como embasamento à proposta analítica}

A relação entre análise e performance musical tem sido um dos temas mais intrigantes da Musicologia. Desde a década de 1990, teóricos, analistas, musicólogos e especialistas das práticas interpretativas têm colaborado com reflexões e publicações sobre esse tema, que ainda carece de atenção do meio acadêmico. A maneira como esta relação tem sido tratada em publicações acadêmicas da área musical continua sendo alvo de questionamentos em virtude das ideologias e métodos que têm acompanhado o desenvolvimento dos estudos em Análise e Performance Musical. Esse desenvolvimento tem ocorrido com base numa diversidade de vertentes analíticas, que têm servido àquelas interessadas pela articulação de conhecimentos relacionados a ambos os domínios de estudo.

Estudos em Análise e Performance Musical podem ser encontrados de fins do século XIX a inícios do século $X^{1}$. Desde então, a ideia da análise musical como um procedimento com potencial de colaborar com a superação de desafios em performance é revelada por publicações relacionadas a diferentes vertentes analíticas. Na década de 1990, num período fortemente marcado pela crítica às propostas formalistas em Análise Musical, vimos o surgimento de importantes publicações sobre a relação entre análise e performance (RINK, 1995; LESTER, 1995; ROTHSTEIN, 1995).

Definimos como estudos literários da subárea Análise Musical aqueles focados na interpretação musical que podem basear-se numa diversidade de objetos de estudo (partitura, gravações, espectrogramas) e modos de perceber o fenômeno musical (BENT; POPLE, 2001). Os estudos literários da subárea Performance Musical atendem a propósitos diversos, como os relacionados a interesses puramente teóricos ou voltados à otimização da performance ou de aspecto a ela atrelado (PALMER, 1997; GERLING; SOUZA, 2000; GABRIELSSON, 2001). Já os estudos da relação entre as duas práticas constituem o interesse da subárea Análise e Performance Musical (ou interface Análise e

\footnotetext{
${ }^{1}$ Teóricos musicais como Latartara e Gardiner (2007, p. 56) reconheceram o interesse de etnomusicólogos pelo estudo da conexão entre análise e performance musical em fins do século XIX.
} 
Performance), considerada um domínio híbrido de estudos, que pode atender a ambos os interesses mencionados.

Nos estudos de Heinrich Schenker (2004 [1922]; 2005 [1924]) vemos o interesse por abordagens analíticas com o propósito de dar suporte ao performer musical. Reconhecemos neste teórico a ideia da análise musical como um procedimento indispensável ao performer. Desde pelo menos a década de 1930, a análise estrutural foi um procedimento imprescindível à qualidade e à validade de uma performance, conforme atestado por diferentes publicações relacionadas à corrente estruturalista dos estudos em Performance Musical. Contudo, desde a década de 1990, autores como Rink (1995) têm admitido certas limitações nestas abordagens focadas no exame da estrutura, principalmente quando seu propósito é contribuir de maneira significativa para a construção de uma performance musical. Porém, as abordagens analíticas embasadas na ferramenta analítica de Schenker, que procuram ilustrar a relevância desta proposta à abordagem de questões pragmáticas em performance (modelagem sonora) não têm sido descartadas por diferentes especialistas das práticas interpretativas e da Análise Musical (RINK, 1994; HOOD, 2014; SWINKIN, 2016).

A ideia da análise musical (desde a mais sistemática até a mais intuitiva) como subsídio para a performance não constitui uma unanimidade entre os músicos. Há performers que assumiram um posicionamento cético quanto à valorização da análise musical no processo de construção de uma performance musical. Um exemplo "drástico" desse ceticismo transparece no estudo de Carolyn Abbate (2004), que viu na análise formalista uma maneira de "domesticar" a experiência de performers. Limitada à sua experiência como performer, essa especialista defendeu a não produção de significados de ordem estrutural durante uma de suas performances. A ideia de que a análise "nada tem a oferecer" ao performer também foi discutida por Rink (1995); no entanto, ao contrário de Abbate, Rink tem se dedicado à elaboração de propostas que buscam e defendem a interlocução entre análise e performance musical.

No grupo dos que defendem a possibilidade de contribuição da análise musical para a performance podemos admitir uma diversidade de posicionamentos e encontrar uma relação com diferentes vertentes dos estudos sobre a interface análise/performance musical. Um primeiro grupo arquetípico seria a vertente estruturalista, cuja nomenclatura 
sugere o peso demasiado conferido ao conhecimento da estrutura no processo interpretativo. Este ideal esteve presente na obra de teóricos musicais da década de 80 , como Larson (1983, p. 45), Narmour (1988, p. 319) e Berry (1989, p. 6). Este último preconizou o relacionamento entre análise e performance como uma "via de mão única", cabendo ao performer a tarefa de reproduzir uma compreensão analítica baseada no ideal de racionalidade. Contudo, um aspecto importante de sua abordagem nos revela a visão em favor do potencial da análise estrutural na abordagem de desafios como a seleção de estratégias voltadas à modelagem da articulação, da dinâmica e o estabelecimento da agógica (BERRY, 1989, p. 3).

Tal possibilidade também foi considerada por especialistas que aderiram a um posicionamento flexível frente a diversos pressupostos estruturalistas. Entre meados da década de 80 e 90, a história dos estudos em Análise e Performance nos mostra uma reação de diferentes estudiosos frente às posturas preconizadas pela vertente estruturalista. Podemos reconhecer em Rink (1990; 1995) e alguns de seus colaboradores (LESTER, 1995; ROTHSTEIN, 1995) o questionamento frente à necessidade de realização de uma rigorosa análise da estrutura como garantia de qualidade de uma performance musical. Qual tipo de análise pode colaborar à construção de uma performance musical ou servir de subsídio aos interesses do performer aparece como questão tratada por diferentes estudiosos, como Schmalfeldt (1985; 2002, p. 54), Rink (1990;1995), Lester (1995) e Rothstein (1995). Notamos em tais autores os esforços por uma abordagem diferenciada acerca do tratamento conferido à figura do performer (e da performance) em relação à proposta de teóricos estruturalistas que assumiram uma postura autoritária nos estudos em análise e performance. Também o incentivo a uma abertura interpretativa a tipos e modos de conhecimento nem sempre contemplados pela vertente estruturalista.

Tanto Schmalfeldt (1985) quanto Rink (1995) demonstraram novas possibilidades de tratamento no discurso analítico relacionado à performance musical. A possibilidade de interlocução entre análise e performance passou a ser considerada por Schmalfeldt (1985) e Lester (1995) como um caminho que poderia levar a uma contribuição mais significativa aos interesses do performer e do analista. Também podemos notar nas críticas de Cook (1999, p. 17) a discussão sobre esta possibilidade de interlocução. Enquanto o exame rigoroso da partitura representou o foco dos estudos relacionados à 
vertente estruturalista, pesquisadores como Lester (1995), Schmalfeldt (2002), Cook (2013) e Hood (2014) demonstraram o potencial de colaboração da performance nos empreendimentos analíticos e teóricos.

A partir de uma consciência histórica acerca de aspectos e problemáticas que permearam o desenvolvimento da Análise e Performance Musical, o propósito deste artigo centra-se no oferecimento de análise musical, embasada na proposta de Schenker a fim de evidenciar o seu potencial na abordagem de questões pragmáticas em performance. Para nossa discussão, escolhemos como objeto de estudo o Praeambulum da Partita n. 5 para teclado, de J. S. Bach, cuja notação musical revela certos desafios em decorrência de sua natureza notacional, caracterizada pela ausência de indicações das nuances de execução relacionadas à dinâmica, à agógica e à articulação. Outras questões do âmbito interpretativo também serão consideradas, já que integram o conjunto de desafios colocáveis ao performer no decorrer de seu processo interpretativo.

\section{Justificativa à metodologia adotada - o amálgama entre diferentes possibilidades analíticas e sua relevância aos desafios da performance}

O propósito central do presente estudo é demonstrar a possibilidade de colaboração mútua entre análise e performance musical. Defendemos a hipótese em favor da possibilidade de colaboração da análise da estrutura e do estudo de gravações no tratamento de desafios em performance e análise musical. Conforme tratado, anteriormente, o caminho que parte da audição estrutural de gravações à elaboração analítica também tem se mostrado de grande valia aos propósitos dos analistas, principalmente, quando estes têm como alvo a elaboração de uma análise sensível aos interesses de performers.

Tanto estudiosos vinculados à vertente Estruturalista quanto aqueles que têm defendido um posicionamento mais flexível diante da chamada análise rigorosa da estruturação musical têm destacado o potencial de colaboração do exame da estruturação musical ao tratamento de desafios da performance. A compreensão da movimentação das linhas, do objetivo dos movimentos, a modelagem da dinâmica, da articulação e o estabelecimento da agógica representam exemplos de alguns destes desafios (BERRY, 1989; CONE, 1968; HOOD, 2014). 
A fim de conceber uma elaboração analítica sensível aos desafios mencionados, selecionamos procedimentos segundo a ferramenta de análise schenkeriana. Para as autoras, esta ferramenta volta-se à abordagem de aspectos que podem trazer importantes contribuições à construção de uma performance musical, por exemplo a compreensão acerca da direcionalidade e objetivos do movimento linear. Sabendo do potencial dos conhecimentos dos eventos situados no plano frontal e médio para a tomada de decisões performativas (HOOD, 2014, p. 5; SWINKIN, 2016), boa parte dos exemplos que serão aqui expostos se fundamentará na percepção do plano frontal em relação a outros eventos da superfície e aspectos expressivos.

A questão relacionada à compreensão rítmica não será ignorada, já que este conhecimento tem profundas implicações para o estabelecimento de agrupamentos, e consequentemente para a fluidez de frases musicais. Para tal, nos basearemos no estudo de Burkhart (1994) que se mostrou relevante para a abordagem desta questão, bem como para os problemas conceituais da obra em estudo ${ }^{2}$. Assim, eventos relacionados às vozes condutoras serão considerados a partir de sua interlocução com a métrica. Como ocorre com outros pesquisadores dos estudos em análise-performance, será considerada aqui uma gama mais ampla dos conhecimentos estruturais com potencial de colaborar aos desafios da modelagem sonoro-expressiva.

A fim de tornar a elaboração analítica significativa aos interesses de performers e analistas, nossa proposta se baseará no estudo comparativo de gravações. Entendemos que tal estudo pode colaborar à compreensão da movimentação linear e, consequentemente, à representação gráfica numa perspectiva schenkeriana. A modelagem expressiva a tratar nesta análise se baseará em diferentes concepções interpretativas, vindas de performers renomados ${ }^{3}$. Podemos adiantar que o contato com

\footnotetext{
2 Entendemos como "problemas conceituais" (RINK, 2002, p. 39) aqueles relacionados às possíveis dificuldades que um performer e/ou analista pode enfrentar para nomear ou conferir significados à determinadas estruturas. Este estudo teve como um de seus propósitos observar as implicações à performance do reconhecimento de eventos métricos, por exemplo o tempo adicionado e a elisão, ambos tratados por Burkhart (1994, p. 3).

${ }^{3} \mathrm{O}$ presente estudo se baseia em gravações dos pianistas Murray Perahia (BACH, 2009), Andràs Schiff (BACH, 1987) e Claudio Arrau (BACH, 1993). A gravação de Perahia foi selecionada em função de seu envolvimento com a ferramenta analítica de Schenker (FINANE, 2019). Com isto, buscou-se observar em sua performance uma aproximação com um "estilo estrutural" de performance. Sabendo-se da relação de András Schiff com um estilo retórico de performance (MATSCHULAT, 2015), buscamos verificar uma aproximação com certas práticas interpretativas do período Barroco. Já a gravação de Arrau foi selecionada
} 
os elementos expressivos da performance favoreceu uma concepção mais ampla de forma musical do que aquelas focadas apenas nos conhecimentos estruturais. Assim, vários dos exemplos evidenciarão a inter-relação entre vozes condutoras e elementos expressivos da performance. Com o intuito de favorecer esta percepção, faremos uso do software Sonic Visualiser e seus gráficos de oscilações de dinâmica ${ }^{4}$ e agógica ${ }^{5}$.

Com fundamentos nas discussões acerca do papel da performance nas análises musicais, é um propósito nosso ilustrar a influência das decisões performativas geradas a partir de gravações para a construção de uma concepção analítica. Se durante décadas musicólogos silenciaram em relação às contribuições de performers para o processo interpretativo de teóricos e/ou musicólogos, buscaremos no estudo a seguir resgatar este potencial de contribuição, mostrando inclusive os impactos das decisões de realização na interpretação estrutural. Assim, o processo simbiótico entre as atividades da análise e performance musical será considerado uma maneira de contribuir para resolver a separação entre ambos os discursos ${ }^{6}$.

\section{Proposta analítica ao Praeambulum da Partita n. 5, de J. S. Bach: a interlocução entre performance e análise musicais como possibilidade analítica}

Composto em 1730, o Praeambulum da Partita n. 5 para instrumentos de teclas ${ }^{7}$, de J. S. Bach, apresenta em seu início uma figuração similar àquela contida em muitas de suas tocatas para cravo. A rápida sucessão de notas e figurações em arpejos são elementos bastante recorrentes nas tocatas do compositor, também presentes ao longo desta peça. Esta também chama a atenção pela figuração a ser executada por meio da alternância entre ambas as mãos, aspecto que novamente remete à similaridade deste prelúdio com

\footnotetext{
em virtude do contraste interpretativo em relação às demais, possibilitando a inclusão de ambiguidades interpretativas numa análise musical.

${ }^{4}$ Para gerar os gráficos de amplitude (dinâmica) acessamos os plugins utilizados pelo projeto Mazurka, especificamente o recurso "Power Curve". Este recurso não é nativo do software Sonic Visualiser, sendo necessária a sua instalação. Disponível em: <http://www.mazurka.org .uk/software/sv/plugin/>.

${ }^{5}$ Para realizar a avaliação das variações de andamento optou-se pela marcação do primeiro tempo de cada compasso, ao invés de cada tempo. A elaboração dos gráficos representativos da agógica baseou-se em recursos já disponibilizados pelo software Sonic Visualiser.

${ }^{6}$ A abordagem deste problema nos estudos em Análise e Performance Musical foi tratada por Tong (1994).

${ }^{7}$ Para a realização deste estudo nos baseamos na edição Urtext, publicada em 1976 pela Bärenreiter-Verlag Karl Vötterle GmbH \& Co. KG (Kassel). Ver Bach (1976 [1730]). Na análise que será exposta, consideraremos o Dó3 como o Dó central.
} 
diferentes tocatas de Bach. Esse aspecto pode ser notado por meio de uma breve comparação entre o Praeambulum e os compassos iniciais da Tocata em Ré menor (BWV 913), de J. S. Bach.

Figura 1 - Figurações em arpejos e caracterizadas pela alternância de mãos em diferentes excertos de obras de Bach.

Fig. 1a - Excerto do Praeambulum (compassos 1-8).

1. Praeambulum
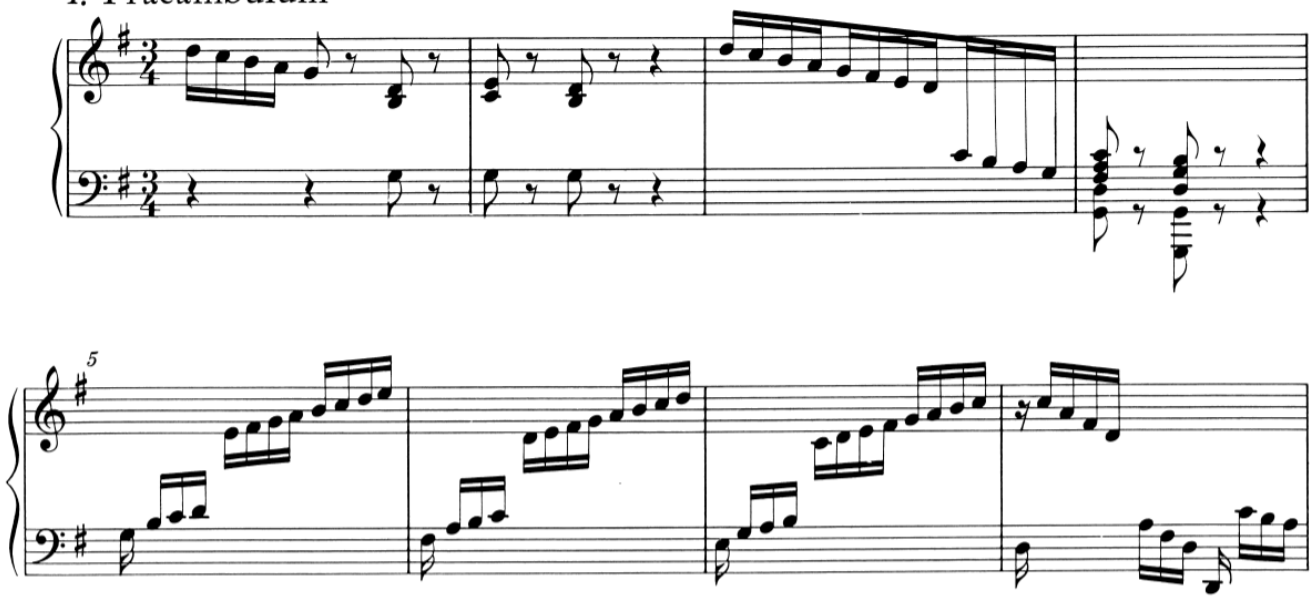

Figura 1b - Excerto da Tocata em Ré menor (BWV 913), compassos 3-7, de J. S. Bach.
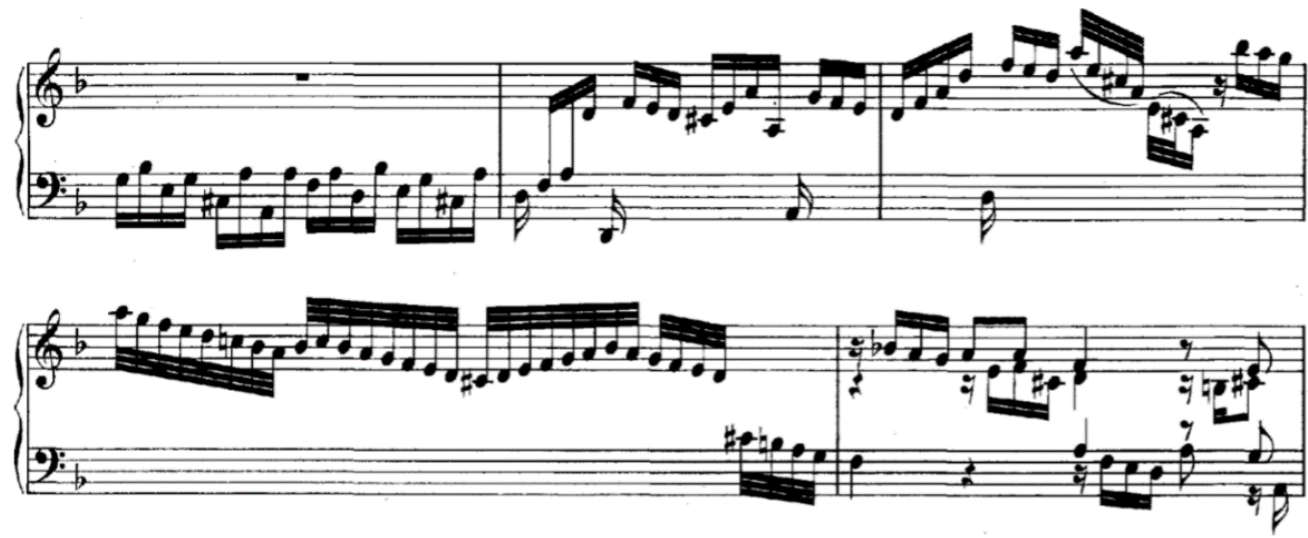

Fonte: Fig. 1a - Bach (1976 [1731] e Fig. 1b - Bach (1890 [1708]).

O caráter alegre e brilhante sugerido pelos compassos iniciais coincide com a interlocução entre diferentes elementos da estrutura. Sob o prolongamento da harmonia de tônica é possível notar a alternância entre diferentes registros e figurações que 
conferem dinamicidade e contraste. Diferentes artifícios corroboram a sensação de expectativa, como a inclusão de figurações melódicas (apojaturas, compassos 2 e 4) e as pausas que concluem os compassos 2 e 4. Na gravação de András Schiff (BACH, 1987), notamos uma ênfase dada à apojatura e o emprego de distintos níveis de dinâmica. Esta distinção, que ocorre após pausas em ambas as mãos, também aparece no retorno desta figuração (compassos 17-20). Na Figura 2, baseada na gravação de Schiff, apresentamos uma representação das vozes condutoras (plano frontal) e de sua interlocução com a dinâmica e a agógica. Podemos notar a presença dos acoplamentos, indicativos do sentido de direcionamento e prolongamento lineares, que acompanham distintos níveis de dinâmica. Na Figura $2 b$ temos a representação das oscilações de dinâmica e da agógica; nela é possível notar o emprego de um breve ritardando nos finais dos compassos 2 e 4 .

Figura 2 - Interlocução entre vozes condutoras, agógica e oscilações de dinâmica baseadas na gravação de Schiff (compassos 1-4).

Fig. 2a - Refrão (compassos 1-4) baseado na gravação de Schiff.

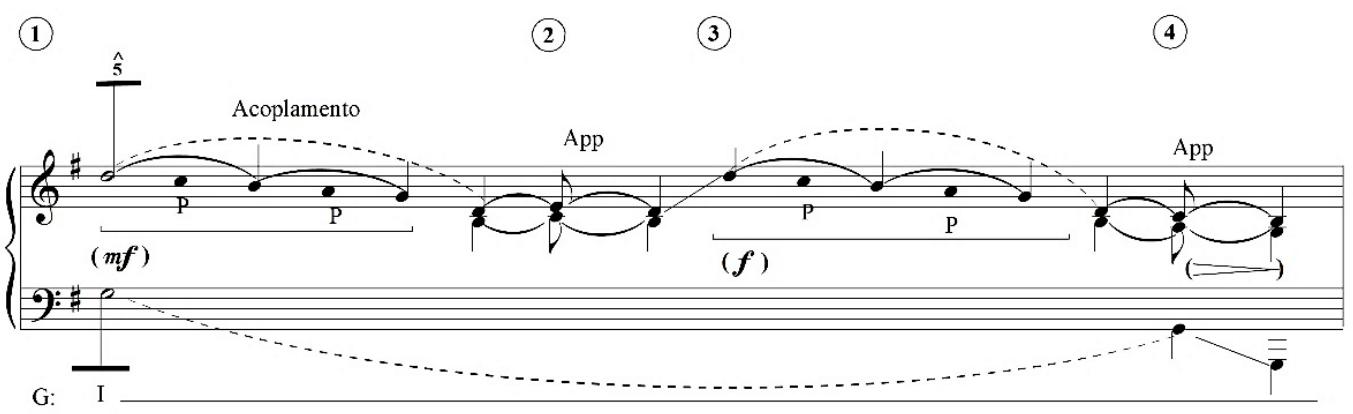

Fig. 2b - Representação das oscilações de dinâmica e agógica (compassos 1-4) em Schiff.

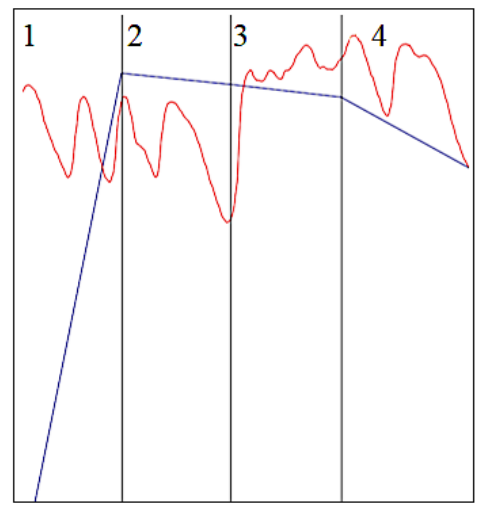

Fonte: Elaboração das autoras. 
Após o refrão, temos o típico movimento em "cascata" (compassos 5-8) presente em muitas obras para teclas de Bach (FORTE; GILBERT, 1982). A partir da gravação de Murray Perahia (BACH, 2009) é interessante notar a proposta de condução melódica conferida por este pianista à linha compreendida entre os compassos 5-8 (registro inferior), coincidente com uma progressão de quarta (registro inferior) e de terça (registro superior). A gravação deste pianista também permite notar o aumento da dinâmica no compasso 8 (Fig. 3c), que apresenta o acorde de sétima de dominante (Fig. 3a) e ponto de chegada linear (finalização de uma progressão de quarta). Também é nítido o decréscimo de dinâmica a partir do compasso 8 em direção à nota sol 2 (registro inferior, compasso 9), fronteiriça do motivo de quinta (representado pelo colchete) e outro ponto de chegada linear. Na gravação de Perahia podemos perceber um sutil diminuendo e ritardando em direção ao objetivo harmônico do compasso 9, delimitando assim o membro de frase compreendido entre os compassos 5-9. Semelhantemente à de Perahia, notamos na gravação de Schiff o emprego de um sutil ritardando e decréscimo da dinâmica em fins do segundo membro de frase (compassos 5-9). A interlocução entre vozes condutoras, variações de dinâmica e agógica é dada na figura 3 a seguir.

Figura 3 - Interlocução entre vozes condutoras, dinâmica e tempo a partir das gravações de Schiff e Perahia (compassos 1-8).

Fig. 3a - Vozes condutoras - Plano frontal (compassos 5-9).

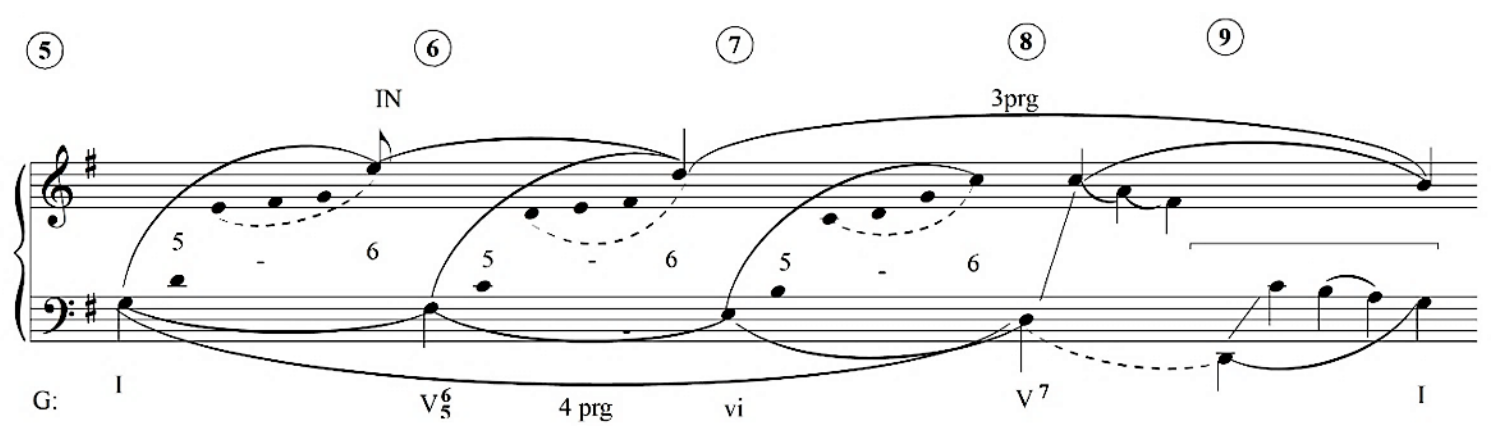


Fig. 3b - Interlocução entre dinâmica e agógica a partir da gravação de Schiff (compassos 5-8).

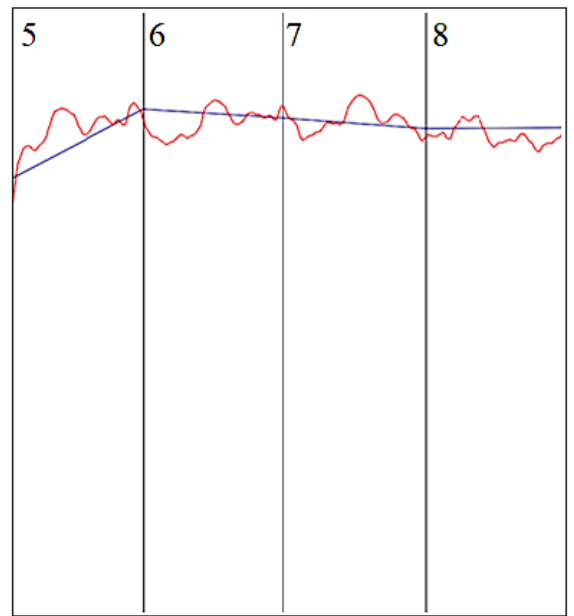

Fig. 3c - Interlocução entre dinâmica e tempo a partir da gravação de Perahia (compassos 5-8).

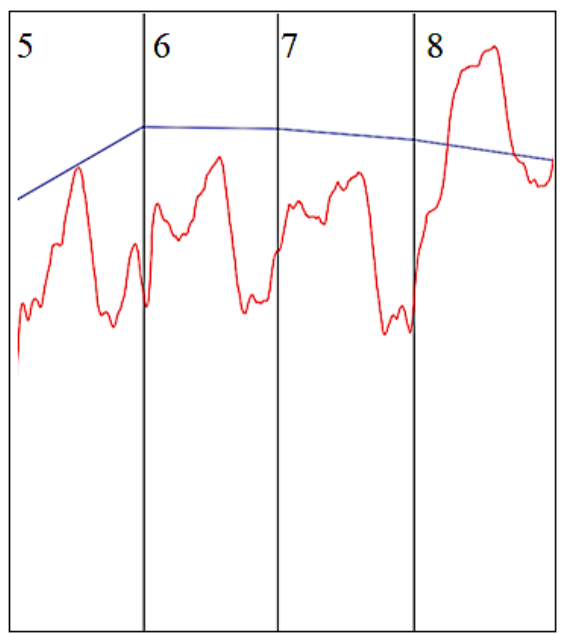

Fonte: Elaboração das autoras.

A partir das propostas de condução melódica presentes nas gravações de Perahia e Schiff elaboramos nossa representação por vozes condutoras. A ideia de primeiros tempos dos compassos como ponto de chegada de movimentos lineares (Fig. 4a) é corroborada pela escuta das gravações do trecho compreendido entre os compassos 9-15. No gráfico de vozes condutoras da figura 4a observamos a presença de prolongamentos melódicos por meio da retenção de uma mesma altura a cada dois compassos (notas Si 3, Lá 3 e Sol 2; registro superior, compassos 9-14). Entendemos que a observação destes prolongamentos, da direcionalidade da linha melódica, dos objetivos harmônicos e lineares poderia colaborar com a seleção de estratégias de dinâmica e de agógica. Um 
exemplo é dado no gráfico do plano frontal (figura 4a), que ilustra o emprego de diferentes níveis de dinâmica a partir do compasso $9^{8}$. Outras estratégias de execução são oferecidas pelos gráficos de dinâmica-agógica. Em Schiff (Fig. 4b) notamos uma dinâmica crescente em direção ao compasso 16, coincidente com acorde dissonante que se resolve no compasso seguinte. Em Perahia (figura 4c), esta resolução é tratada também por meio do emprego de um ritardando, que serve como uma espécie de preparação à entrada do refrão (compassos 17-20). Quanto à articulação, as gravações de Perahia e Schiff mostram uma projeção de certas notas do baixo (compassos 8-15) que se movimentam por meio de intervalos de quinta (Ré, Sol, Do\#, Fá\#, Si, Mi).

Figura 4 - Vozes condutoras e aspectos expressivos (compassos 9-16).

Fig. 4a - Representação de vozes condutoras (plano frontal).

(9)

(10)

(11)

(12)

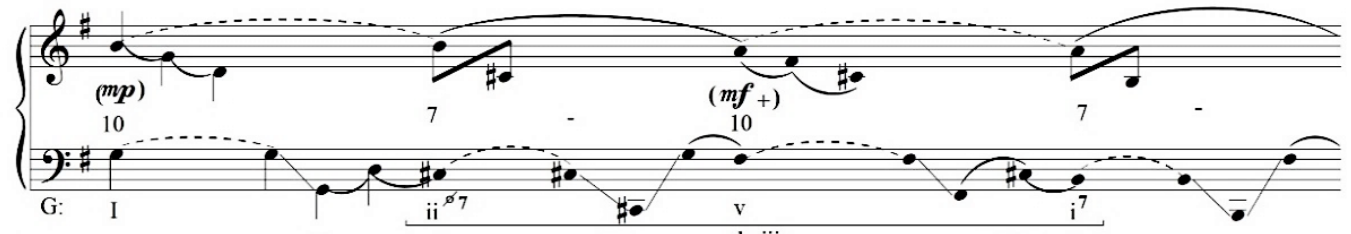

(13)

(14)

(15)

(16)

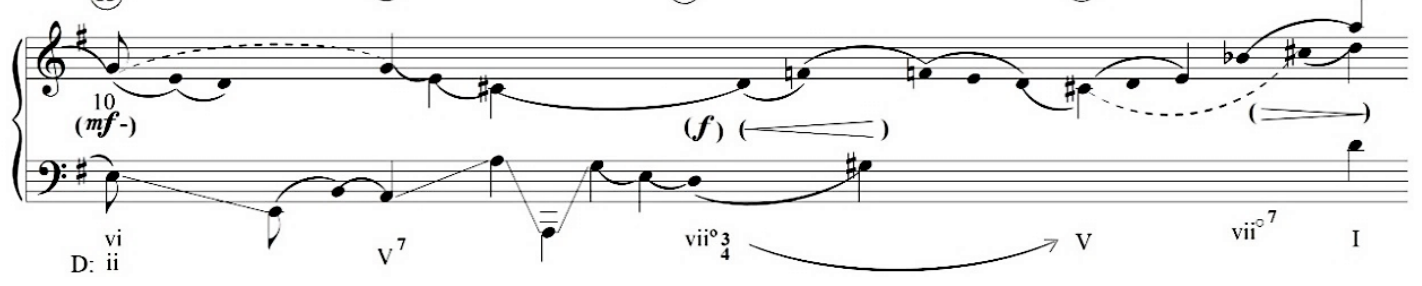

\footnotetext{
${ }^{8}$ No gráfico de vozes condutoras da Figura 4 e de outras que serão apresentadas, foram inseridos sinais de dinâmica aliados aos sinais indicativos de suas nuances (símbolos de mais e de menos ao lado das indicações de dinâmica) a fim de evidenciar a escuta de aspectos expressivos. $\mathrm{O}$ exemplo mencionado baseou-se na modelagem proposta por Schiff.
} 
Fig. 4b - Representação da agógica e das oscilações de dinâmica com base na gravação de Schiff.

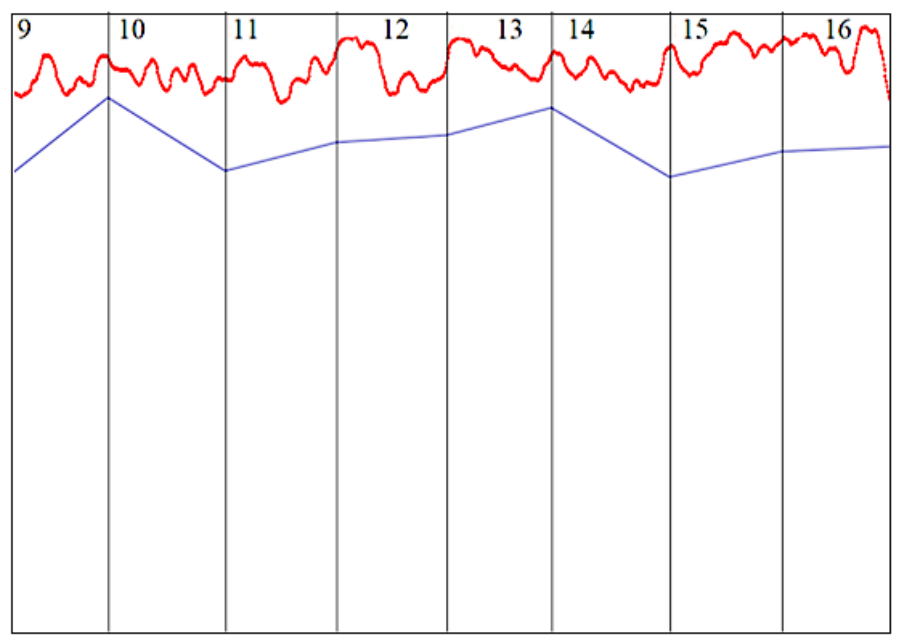

Fig. 4c - Representação da agógica e das oscilações de dinâmica com base na gravação de Perahia.

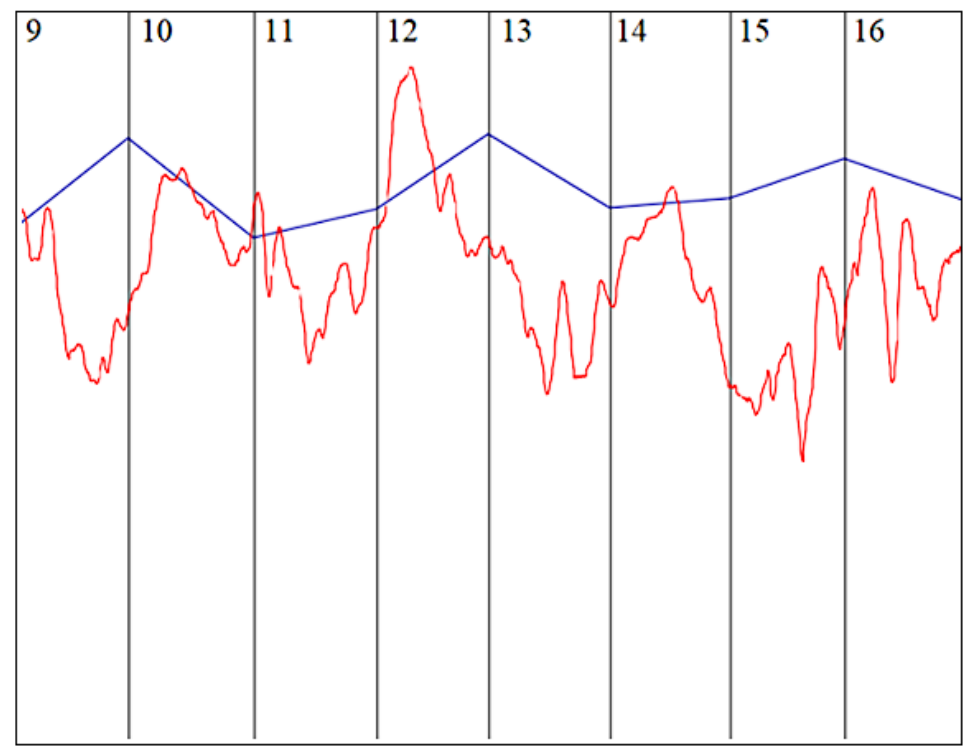

Fonte: Elaboração das autoras.

Após retorno de figuração melódica que remete à frase 1 ou refrão (compassos 1720), uma melodia polifônica (FORTE; GILBERT, 1982, p. 68) é iniciada a partir do compasso 21. Uma compreensão da direcionalidade das linhas é favorecida pela escuta das gravações. A ideia dos primeiros tempos (compassos 22-25) como ponto de chegada dos movimentos é perceptível nas propostas de condução melódica (fraseado) dos performers selecionados para este estudo. Podemos, assim, interpretar o compasso 25 
como um importante ponto de chegada do movimento linear, coincidente com uma cadência autêntica imperfeita (compassos 24-25) num contexto de tonicização em Ré maior. A influência desta percepção, juntamente com as propostas de condução melódica mencionadas, vê-se no gráfico de vozes condutoras da Figura 5a. Entendemos que uma consciência do performer dos eventos mencionados poderia ter a relevância para a seleção de estratégias de dinâmica e agógica. Tanto em Perahia quanto em Schiff notamos o emprego de um ritardando em direção a este importante ponto de chegada do movimento linear e objetivo harmônico (compasso 25), com mais ênfase na interpretação de Perahia. Com base na gravação de Perahia, incluímos no gráfico de vozes condutoras a representação de algumas das nuances oferecidas por este pianista.

Figura 5 - Interlocução entre vozes condutoras e aspectos expressivos (compassos 21-26).

Fig. 5a-Plano frontal.

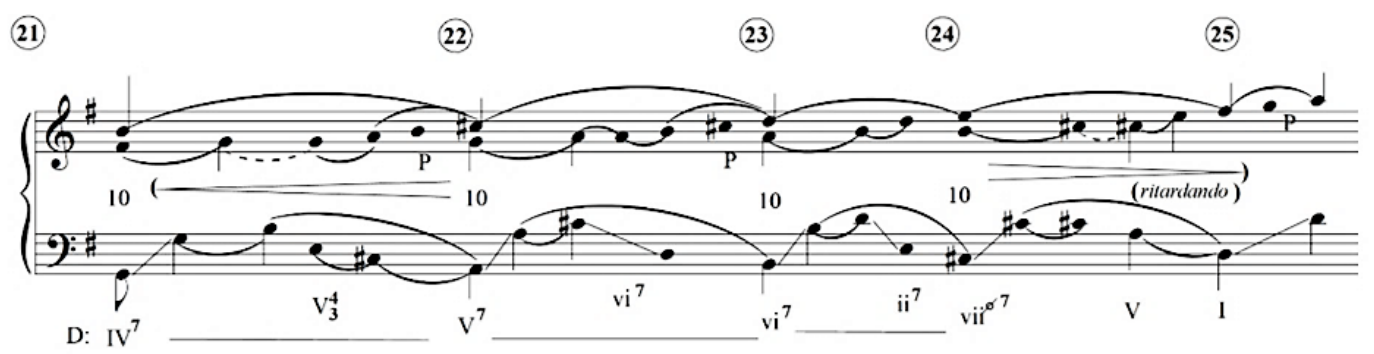

Fig. 5b - Representação da agógica e oscilações de dinâmica por Schiff.

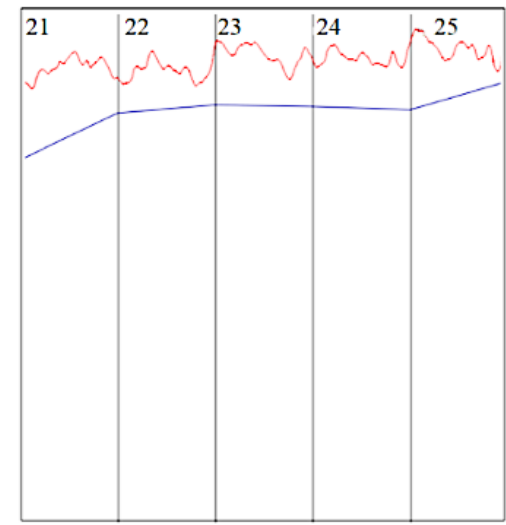


Fig. 5c - Representação da agógica e oscilações de dinâmica por Perahia.

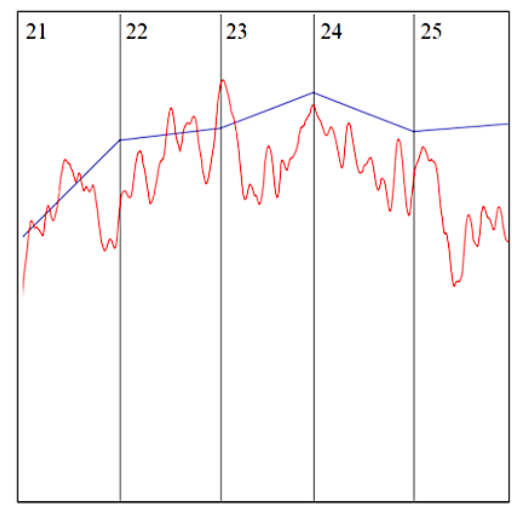

Fonte: Elaboração do autoras.

A escuta das propostas de condução melódica (ou fraseado) dos diferentes performers sobre o trecho compreendido entre os compassos 25-29 também nos auxilia no reconhecimento de importantes objetivos lineares, assim como corrobora a ideia de primeiros tempos como pontos de chegada de movimentos lineares. Essa ideia transparece no gráfico de vozes condutoras da Figura 6a, que ilustra movimento por nota vizinha (compassos 26-27) e duas progressões lineares de terça (compassos 27-29), que antecedem uma tonicização para Lá Maior (compasso 29). Entendemos que uma consciência sobre tais pontos de chegada poderia ter sua relevância para a seleção de estratégias de dinâmica, agógica e agrupamentos. Na gravação de Perahia é perceptível o emprego de uma dinâmica crescente gradual a partir do compasso 25 em direção ao compasso 28, acompanhando assim a direcionalidade da linha melódica. Já em Schiff, os compassos que marcam a resolução do acorde de sétima de dominante (compassos 2829) são marcados pelo sutil ritardando e dinâmica decrescente. Tais eventos estão representados no gráfico de vozes condutoras da Figura 6a.

Além das vozes condutoras e de sua interlocução com os aspectos expressivos, outro conhecimento estrutural que poderia ter relevância para a questão do agrupamento de eventos não poderia deixar de ser mencionado: é no trecho compreendido entre os compassos 25-29 que encontramos deslocamento da métrica de sua posição normal com propósito de conferir maior flexibilidade ao fraseado. Assim, o exemplo da Figura $6 \mathrm{~b}$ oferece uma reinterpretação da métrica em favor de diferentes tipos de deslocamentos, 
como a elisão e a métrica adicionada (Burkhart, 1994). Entendemos que uma consciência de tais dispositivos pode colaborar para a compreensão de pontos de partida e chegada dos movimentos (ou conhecimento das fronteiras de diferentes agrupamentos) e, portanto, uma contribuição para o estabelecimento de agrupamentos. Vale ainda mencionar a importante contribuição das propostas de agrupamentos providas pelos performers selecionados.

Figura 6 - Interlocução entre vozes condutoras, métrica e aspectos expressivos (compassos 24-29).

Fig. 6a-Vozes condutoras (plano frontal).
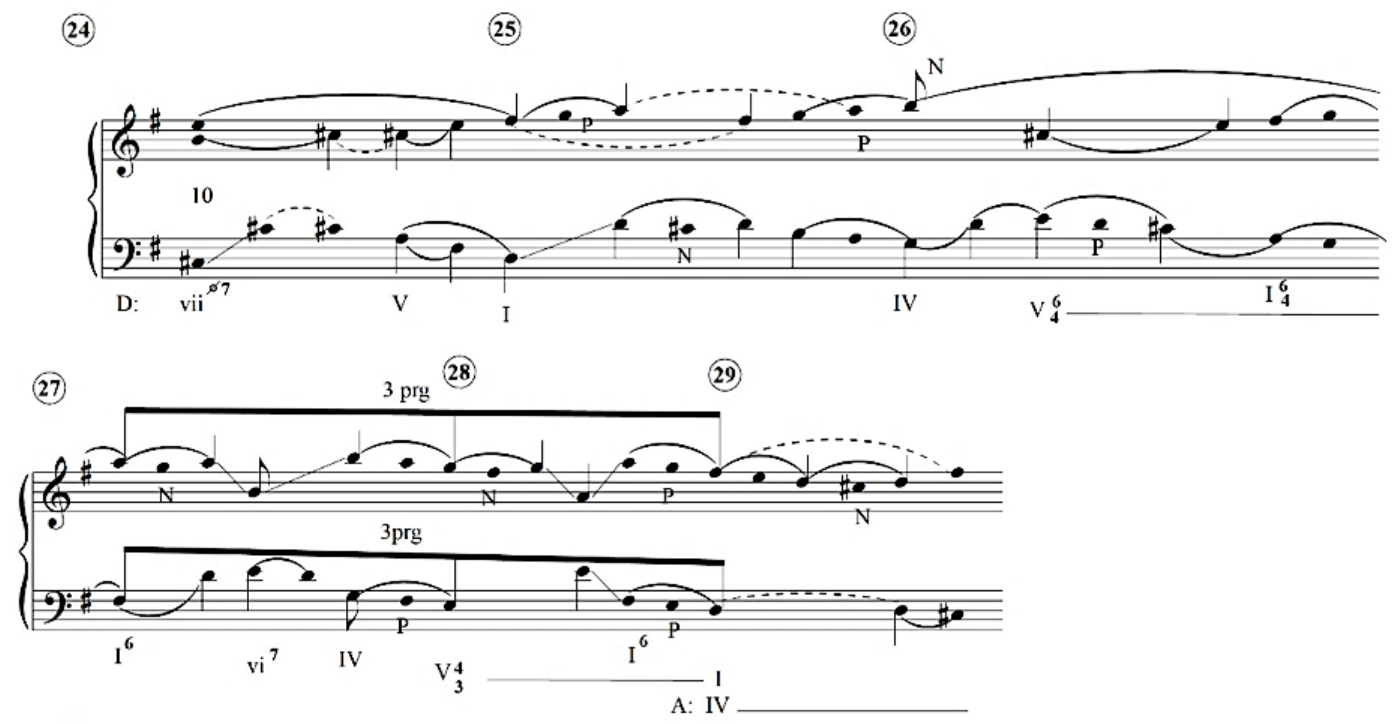

Fig. 6b - Interpretação da métrica.

24

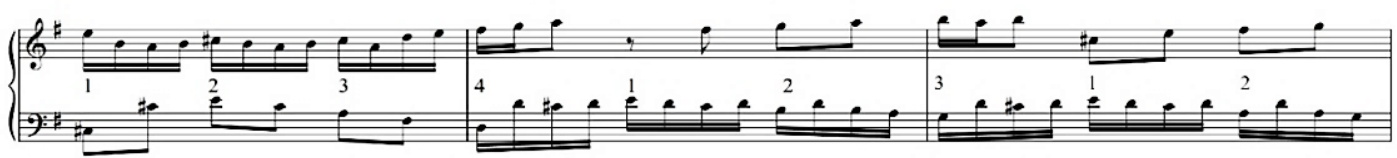

(27)

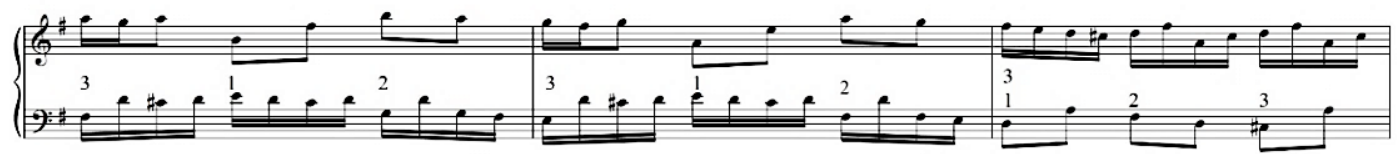


Fig. 6c - Representação da agógica e oscilações da dinâmica por Schiff.

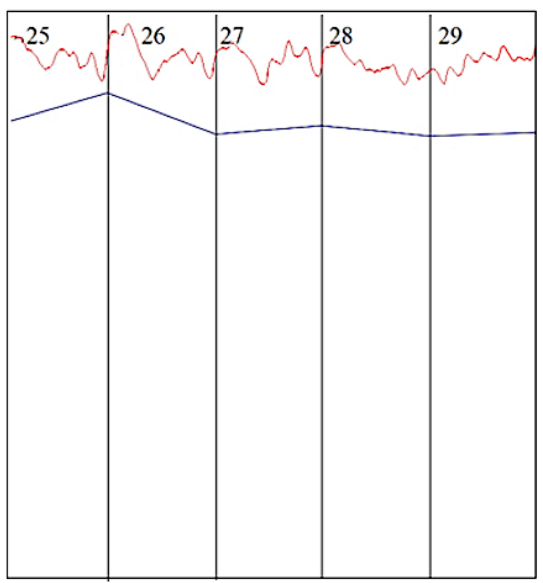

Fig. 6d - Representação da agógica e oscilações da dinâmica por Perahia.

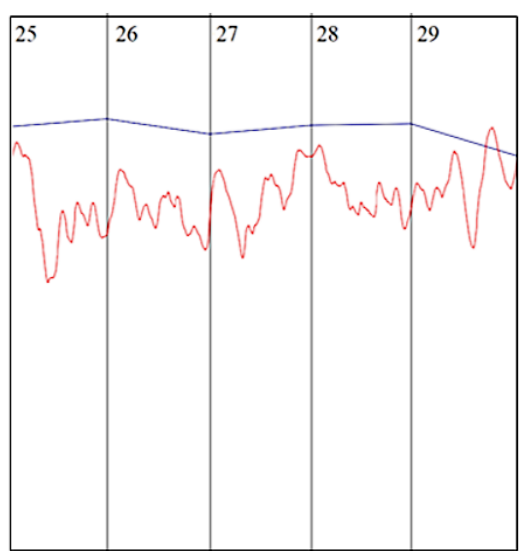

Fonte: Elaboração das autoras.

O trecho que se segue à cadência imperfeita (compassos 28-29) é marcado por uma série de eventos harmônicos e lineares que contribuem com a sensação de dinamismo e propulsão para os compassos 29-37. Tais eventos convergem para o objetivo principal do movimento linear deste trecho, que se encontra no compasso 37, coincidente com uma cadência autêntica imperfeita na tonalidade de Lá Maior ${ }^{9}$. O emprego de dominantes secundárias, movimentação linear ascendente e adensamento da textura (compassos 33-

\footnotetext{
${ }^{9}$ A partir do compasso 29 temos uma tonicização para Lá maior, que abrange os compassos 29-39. O trecho é marcado pela ambiguidade em relação à tonalidade de lá menor em decorrência da subdominante menor do compasso 35 .
} 
37) contribuem para a sensação de maior intensidade emocional ${ }^{10}$, diminuída com a introdução da cadência autêntica imperfeita (compassos 36-37). Uma observação da interlocução entre os eventos lineares e harmônicos dos compassos 33-37 (Fig. 7) corrobora a ideia de uma progressão de quinta, finalizada juntamente com esta cadência. No gráfico de vozes condutoras da Figura 7 é apresentada uma proposta de modelagem da dinâmica e da agógica, fundamentada na análise da estrutura e de gravações. Assim, reconhecemos a escolha interpretativa de uma dinâmica crescente em direção ao compasso 32 , que por sua vez inaugura a frase compreendida pelos compassos 32-37. A partir das gravações de Perahia e Schiff nota-se o emprego de uma dinâmica crescente em direção ao compasso 36, sustentado pelo acorde formado sobre a sensível, assim como pelo decréscimo da dinâmica e de um ritardando em direção a um importante ponto de chegada do movimento linear ou finalização de uma progressão por quintas (compasso 37).

Figura 7 - Vozes condutoras e representação de aspectos expressivos (compassos 27-37).

Fig. 7a-Vozes condutoras (plano frontal).

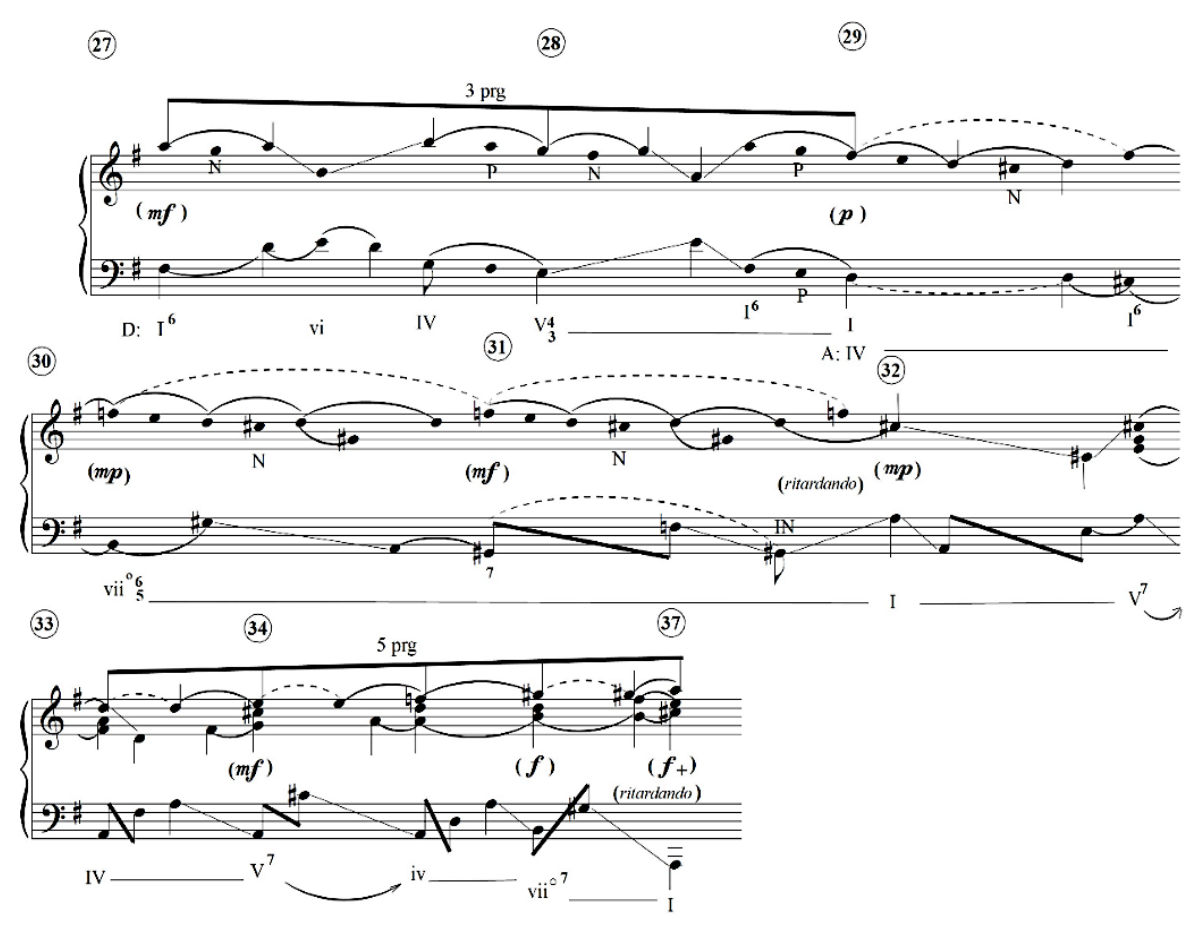

\footnotetext{
${ }^{10}$ A possibilidade de produção de metáforas expressivas a partir do conhecimento da estrutura foi tratada por Swinkin (2016, p. 42): ele defendeu o emprego da ferramenta analítica de Schenker na produção de diferentes tipos de metáforas, como aquelas de ordem cinestésica e expressiva (significados emocionais), além de observar a relação da teoria schenkeriana com a produção de metáforas. Em outras palavras, Swinkin compreende a análise musical como um procedimento com potencial de promover metáforas para as experiências cinestésicas e emocionais.
} 
Fig. 7b - Representação da agógica e oscilações de dinâmica por Schiff.

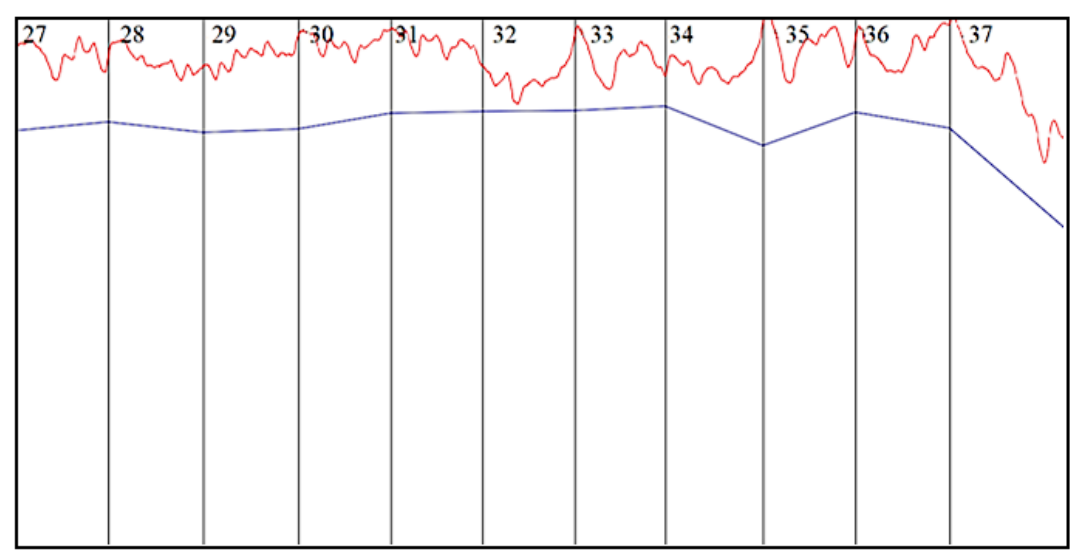

Fig. 7c - Representação da agógica e oscilações de dinâmica por Perahia.

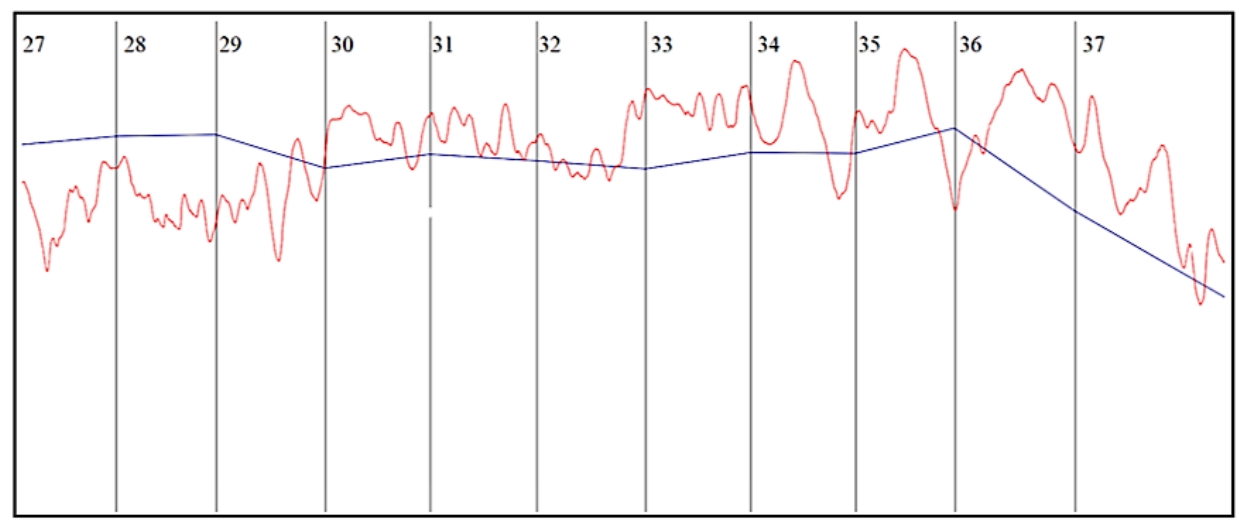

Fonte: Elaboração das autoras.

A partir do compasso 41, encontramos mais elementos que contribuem para a coesão e coerência desta brilhante e complexa composição, dentre os quais podemos mencionar o aparecimento do refrão (compassos 41-44), agora num contexto de tonicização em Mi menor. Outro elemento que remonta ao início da composição também se vê entre os compassos 45-48, cujos eventos lineares se assemelham àqueles utilizados entre os compassos 5-8. Como exemplo, podemos mencionar a repetição do padrão 5-6, que acompanha a progressão de quarta. Contudo, a mudança para a tonalidade menor deste trecho parece corroborar um novo afeto. É no trecho compreendido entre os compassos 49-56 que encontramos uma série de eventos que parecem colaborar para a intensidade emocional, como a constante presença do acorde de sétima de dominante, inseridos num contexto de figuração melódica ascendente (compassos 49-52). Uma 
observação das diferentes propostas de modelagem sonora da Figura 8 nos permite notar o emprego de uma dinâmica crescente a partir do compasso 45 em direção ao compasso 52, coincidente com o acorde formado sobre a sensível. Temos aqui mais um elemento que contribui para a intensidade emocional do trecho. A ideia do compasso 57 como um importante ponto de chegada do movimento linear (término de uma progressão de terça) é corroborada pela escuta das gravações. Nas diferentes gravações selecionadas para este estudo é perceptível tanto o emprego de uma dinâmica decrescente quanto do ritardando em direção ao compasso 57, como ilustrado pelos gráficos de agógica-dinâmica da Figura 8.

Figura 8 - Vozes condutoras e aspectos expressivos (compassos 41-57).

Fig. 8a-Vozes condutoras (plano frontal).
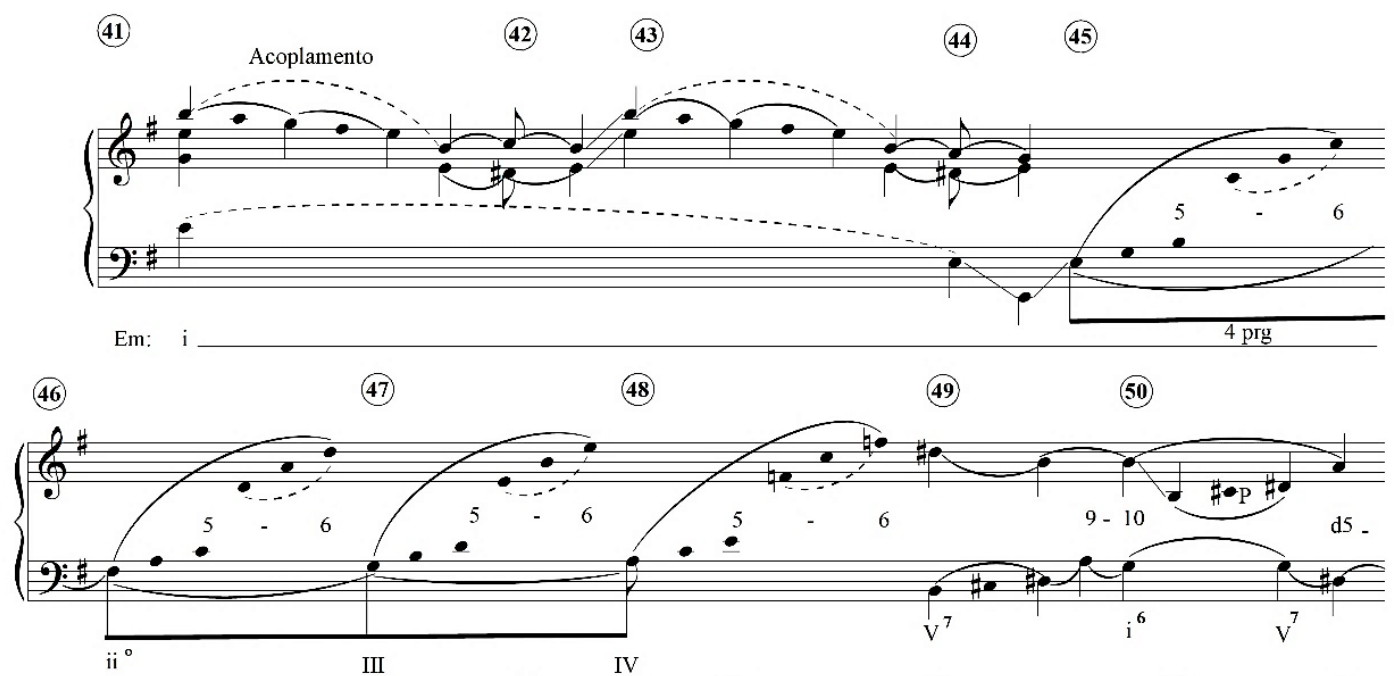

(51)

(52)

(53)

(55)

(56)

(57)

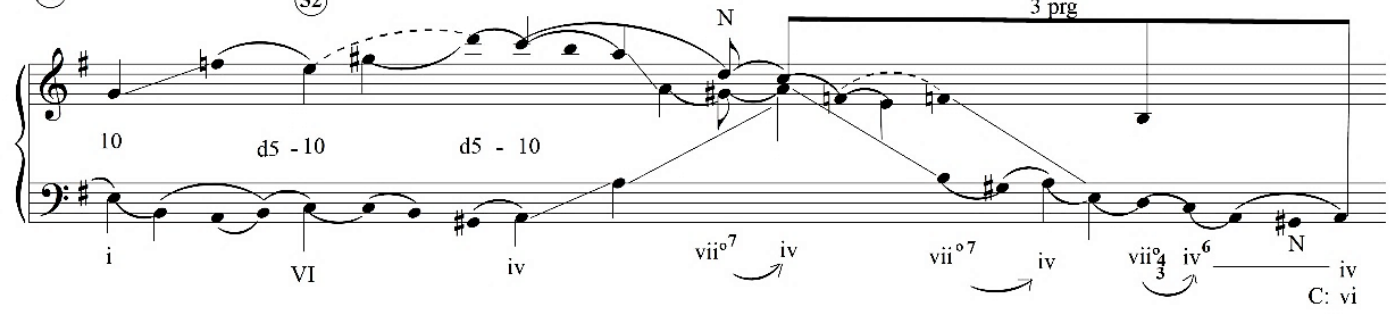


Fig. 8b - Representação da agógica e oscilações da dinâmica a partir de Perahia.

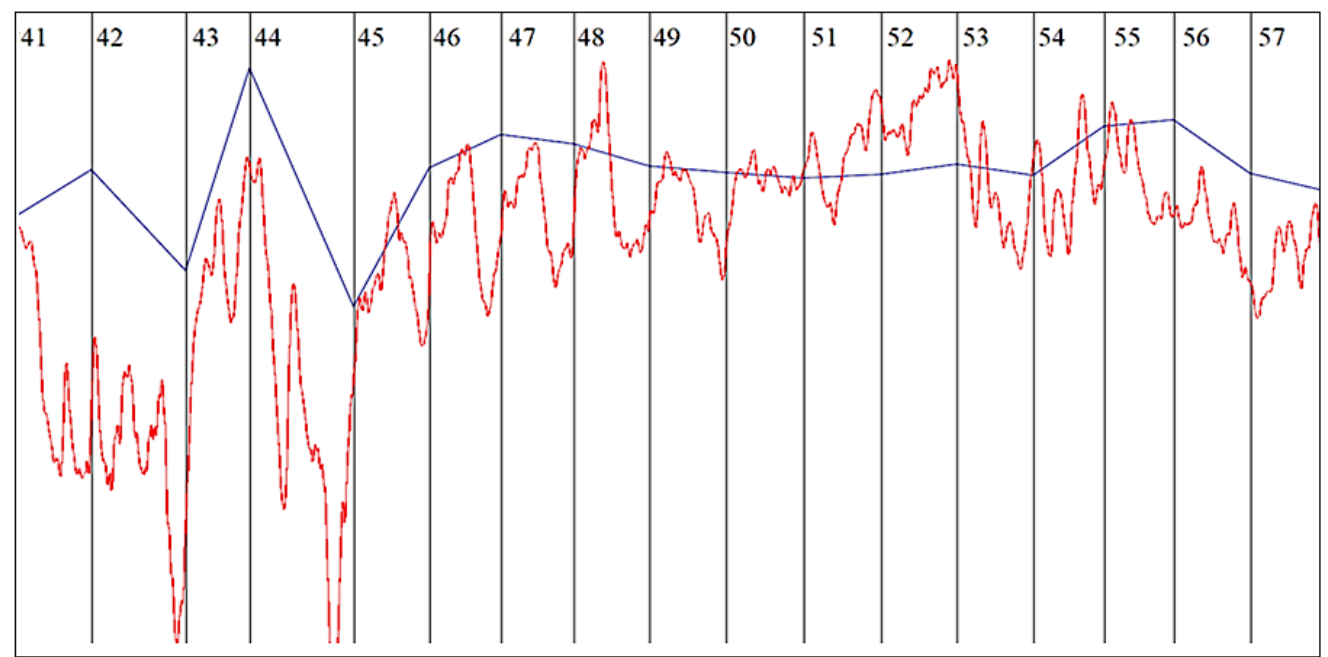

Fig. 8c - Representação da agógica e oscilações da dinâmica a partir de Schiff.

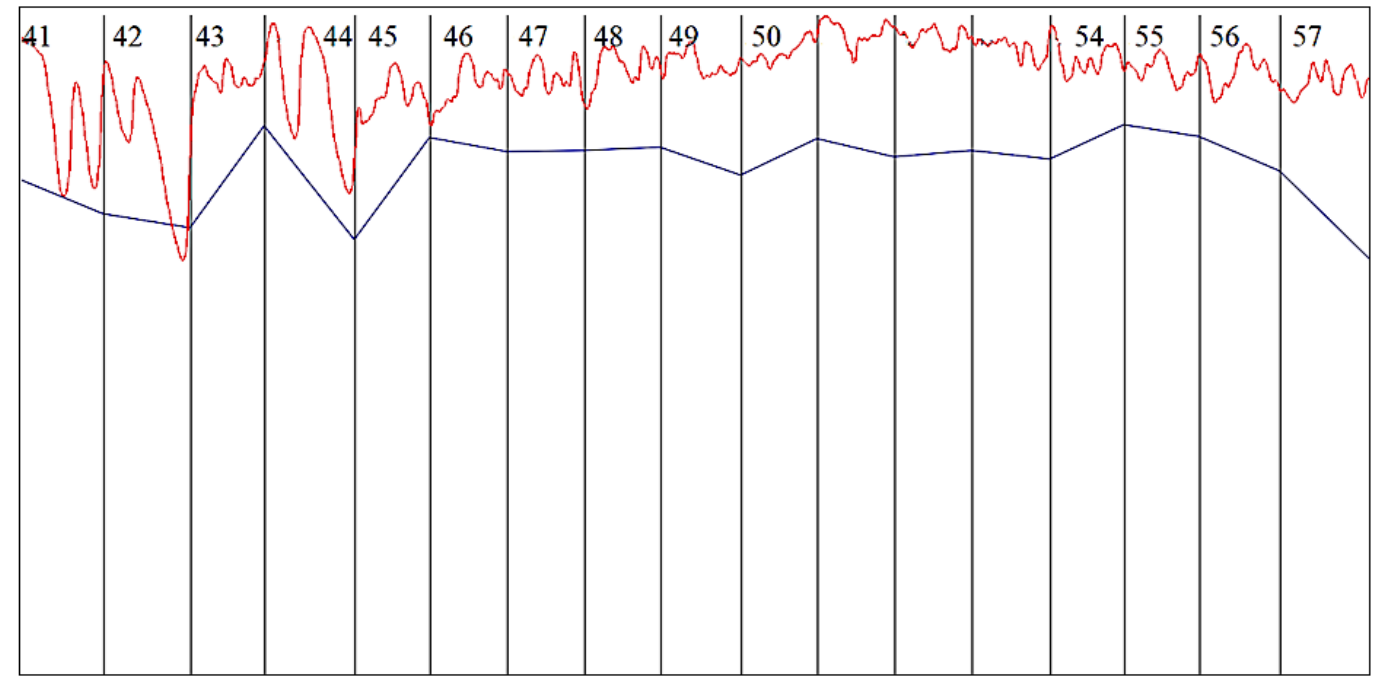

Fonte: Elaboração das autoras.

A atenção conferida aos aspectos expressivos tende a contribuir tanto quanto o conhecimento estrutural para a análise de uma obra musical. Com base nesta ideia propomos na Figura 9 duas possibilidades representativas: uma baseada na ferramenta analítica de Schenker e outra atenta à proposta de articulação oferecida por um dos performers selecionados. Assim, o segundo gráfico oferece uma maneira particular de tratar o emprego das ligaduras, diferindo em alguns aspectos da proposta de Schenker. 
Com base na gravação de Perahia, procuramos representar no segundo gráfico aspectos de sua proposta de condução melódica. A partir da escuta de sua gravação é possível notar como este pianista ressalta as partes fortes de tempo entre os compassos 57-61 (notas Lá, Si, Sol, Dó, Lá, Fá, Sol, Mi, Lá, Fá).

No segundo gráfico, as notas enfatizadas são relacionadas por meio do emprego da ligadura. A proposta de condução melódica de Perahia ao registro superior também é retratada por meio da ligadura que sugere a ideia de primeiros tempos como ponto de chegada de movimentos. No primeiro gráfico, oferecemos uma representação schenkeriana do plano frontal dos compassos 57-61, no qual se nota a presença de uma progressão de quinta (compassos 57-61, registro inferior), antecedida pelo movimento por nota vizinha (compasso 56, registro inferior). A observação da interlocução entre os eventos lineares e harmônicos entre os compassos 61-64 nos permite interpretar este trecho como alinhado à sensação de expectativa, não somente em decorrência do prolongamento de função de dominante, mas também da rápida figuração em semicolcheias. Há um outro aspecto que corrobora esta metáfora: as diferentes propostas de modelagem sonora providas pelos performers. Perahia emprega uma dinâmica crescente entre os compassos 61-64, assim como o ritardando em trecho coincidente com o acorde de sétima de dominante (compasso 64). Outro aspecto a considerar é a proposta de condução melódica oferecida por esse pianista entre os compassos 57-61, na qual se percebe uma ênfase de certas notas do registro superior (Lá, Si, Sol, Dó, Lá, Fá natural, Sol, Mi, Lá Fá natural). Tal ênfase sugeriu a elaboração do gráfico da Figura 9, que novamente apresenta o emprego particular no uso das ligaduras, mas retrata a percepção do fraseado proposto pelo pianista. Em fins deste agrupamento (compassos 60-61) encontramos uma dinâmica decrescente. Dessa maneira, ambos os gráficos da Figura 9 contêm indicações de dinâmica e agógica baseadas na gravação dele. 
Fig. 9 - Representação do plano frontal com base na gravação de Perahia dos compassos 57-65.

Fig. 9a- Vozes condutoras (plano frontal).
(57)
(58)
(59)
60
(61)
62

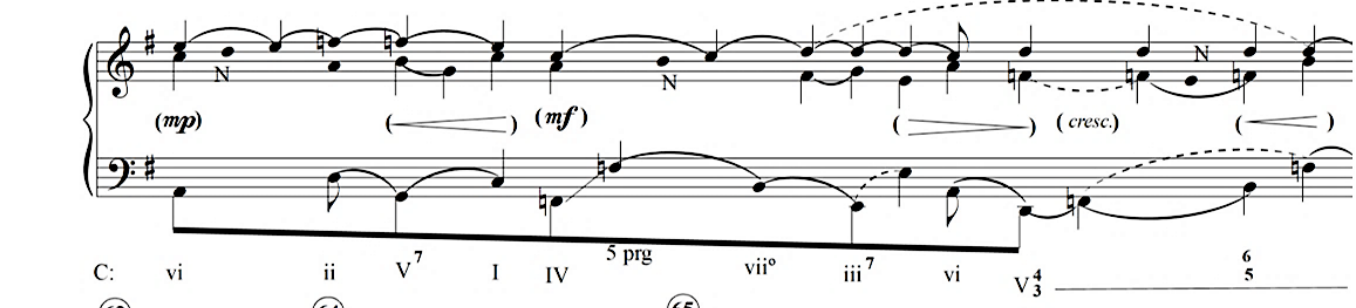

63

(64)

65

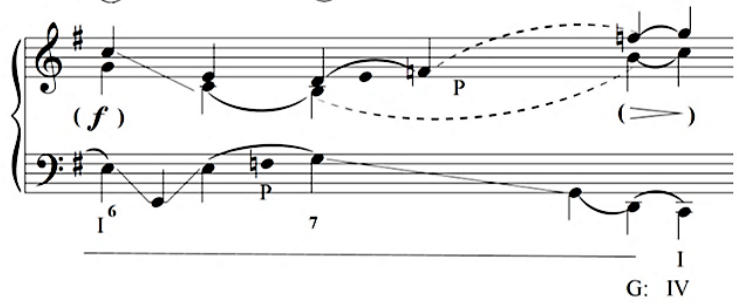

Fig. 9b - Gráfico representativo de aspectos expressivos com base na gravação de Perahia.

(57)

58

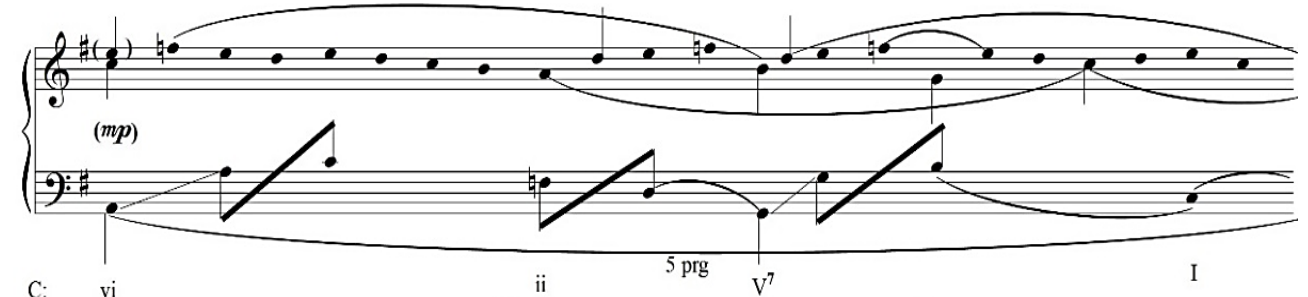

(59)

(60)

61
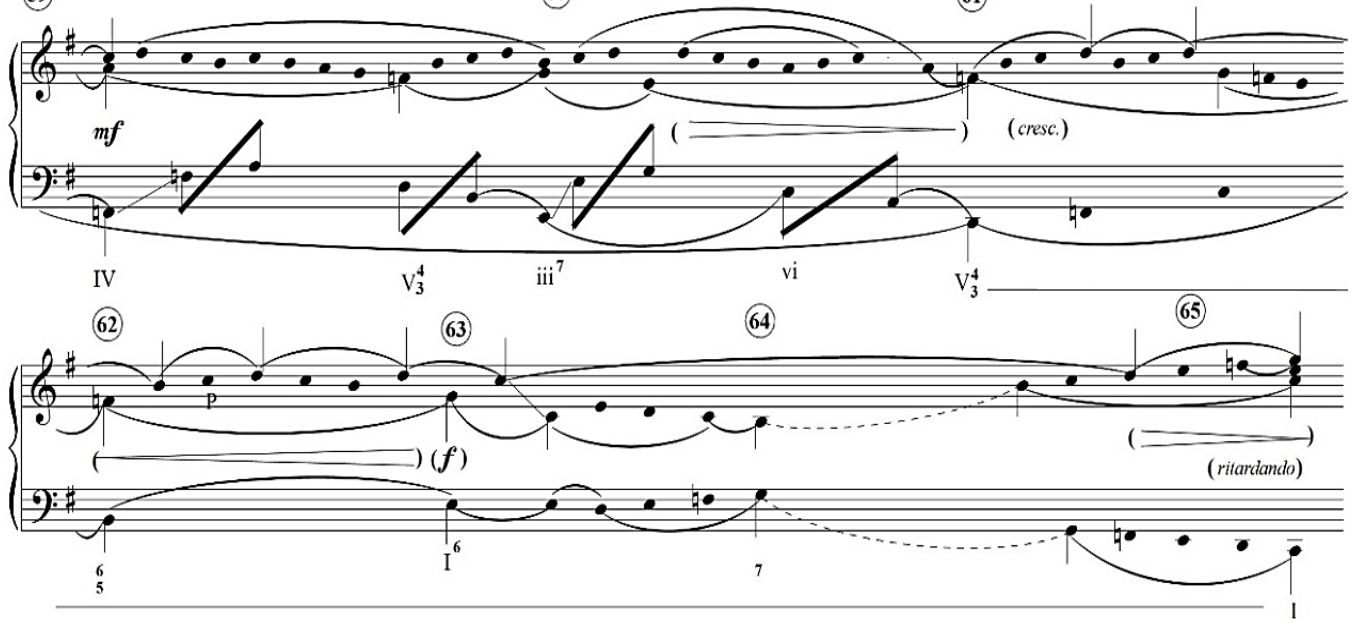
Fig. 9c - Representação da agógica e oscilações de dinâmica a partir da gravação de Perahia.

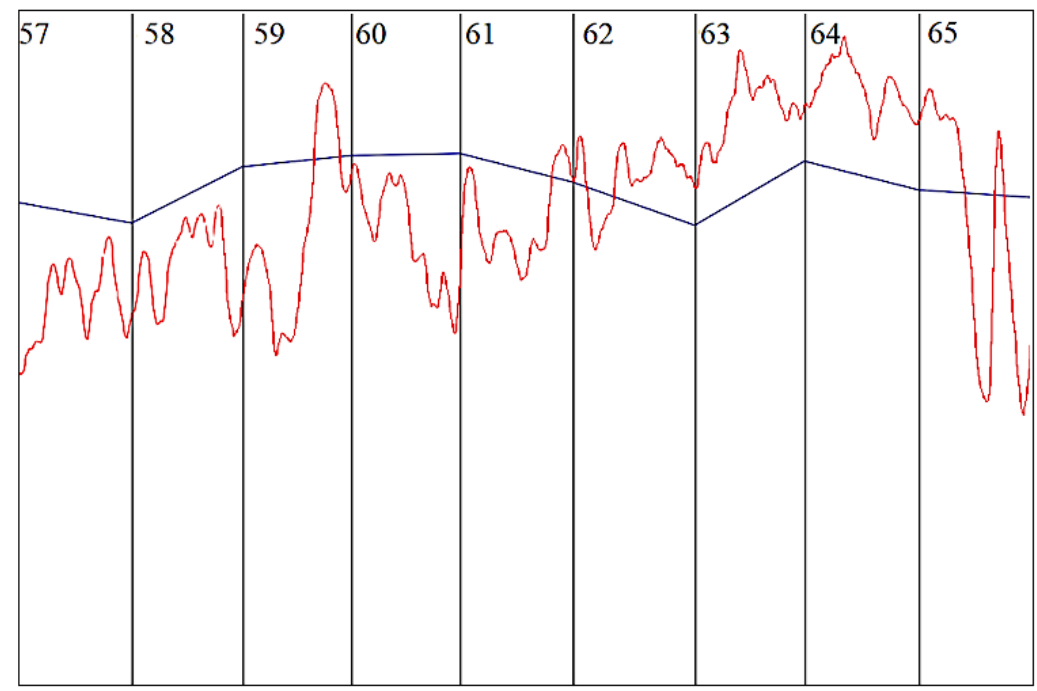

Fonte: Elaboração das autoras.

Se a apresentação do refrão na tonalidade de Sol Maior (compasso 65-68) poderia corroborar a sensação de maior estabilidade, ela é interrompida em decorrência de eventos introduzidos pelo compositor a partir do compasso 73. Apesar da figuração rápida em semicolcheias continuar presente, podemos notar elementos que conferem maior dinamicidade e intensidade emocional ao refrão. Bach apresenta, no trecho entre os compassos 73-78, uma nova textura e mistura de modos, que num contexto de rápida figuração em semicolcheias e dominantes se resolvem em acordes menores (compassos 75-77) e contribuem a ambas as percepções (dinamicidade e intensidade emocional). A sensação de expectativa (compassos 73-86) é reforçada pela cadência suspensiva dos compassos 85-86, antecedida pela harmonia formada sobre o acorde da sensível, que por sua vez contribui para a instabilidade do trecho. Essas observações reforçam a ideia do potencial da análise da estrutura dos eventos da superfície na produção de metáforas emocionais com potencial de contribuir para a expressividade do trecho.

Outro tipo de produção metafórica (de movimento) que gostaríamos de ressaltar vincula-se àquelas características da teoria schenkeriana, a saber, a ideia de pontos de partida e chegada dos movimentos lineares. Entendemos que a busca de uma síntese tende a promover tais conhecimentos com potencial de colaborar para a abordagem de desafios da performance, como a articulação, a modelagem da dinâmica e o 
estabelecimento da agógica. Uma representação dos principais pontos de chegada do movimento linear é dada pelo gráfico de vozes condutoras da Figura 10a.

Nesta interpretação, o trecho posterior à apresentação do refrão em Sol Maior (compassos 65-68) é marcado não apenas pelo movimento por nota vizinha incompleta (Fig. 10a, notas Mi-Ré, compassos 69-70, registro superior), mas por progressões de terça (compassos 70-72) em ambos os registros, que antecipam o compasso 73. Outro importante ponto de chegada do movimento linear encontra-se no compasso 83, também antecedido pelo movimento por nota vizinha incompleta (Fig. 10a, notas Fá natural e Mi, compasso 79-80, registro superior) e progressões lineares de terça nos registros superior e inferior (compassos 80-82). Tais eventos podem ser interpretados como uma espécie de preparação a um objetivo harmônico e linear mais importante (compasso 86), marcado por uma cadência suspensiva, mudança textural e fermata. Dessa maneira, apresentamos na Figura 10 tanto a representação das vozes condutoras quanto dos aspectos expressivos, que ilustram o tratamento conferido à passagem que antecede este fundamental ponto de chegada linear.

Com base nas gravações de Perahia, Schiff e Arrau (BACH, 1993), entendemos que a sensação de expectativa é promovida não apenas pela introdução da harmonia formada sobre a sensível, mas pela modelagem sonora proposta pelos performers (Arrau e Schiff), que tendem a empregar o ritardando, assim como a dinâmica crescente em direção ao compasso 86.

Figura 10 - Vozes condutoras (compassos 69-86) e aspectos expressivos (compassos 83-86).

Fig. 10a-Vozes condutoras (plano frontal).

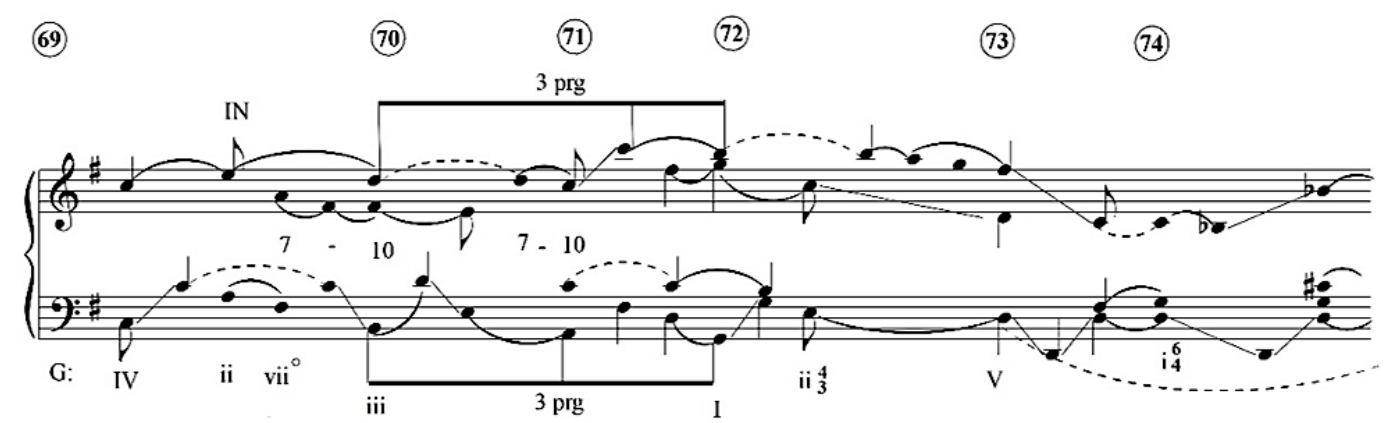




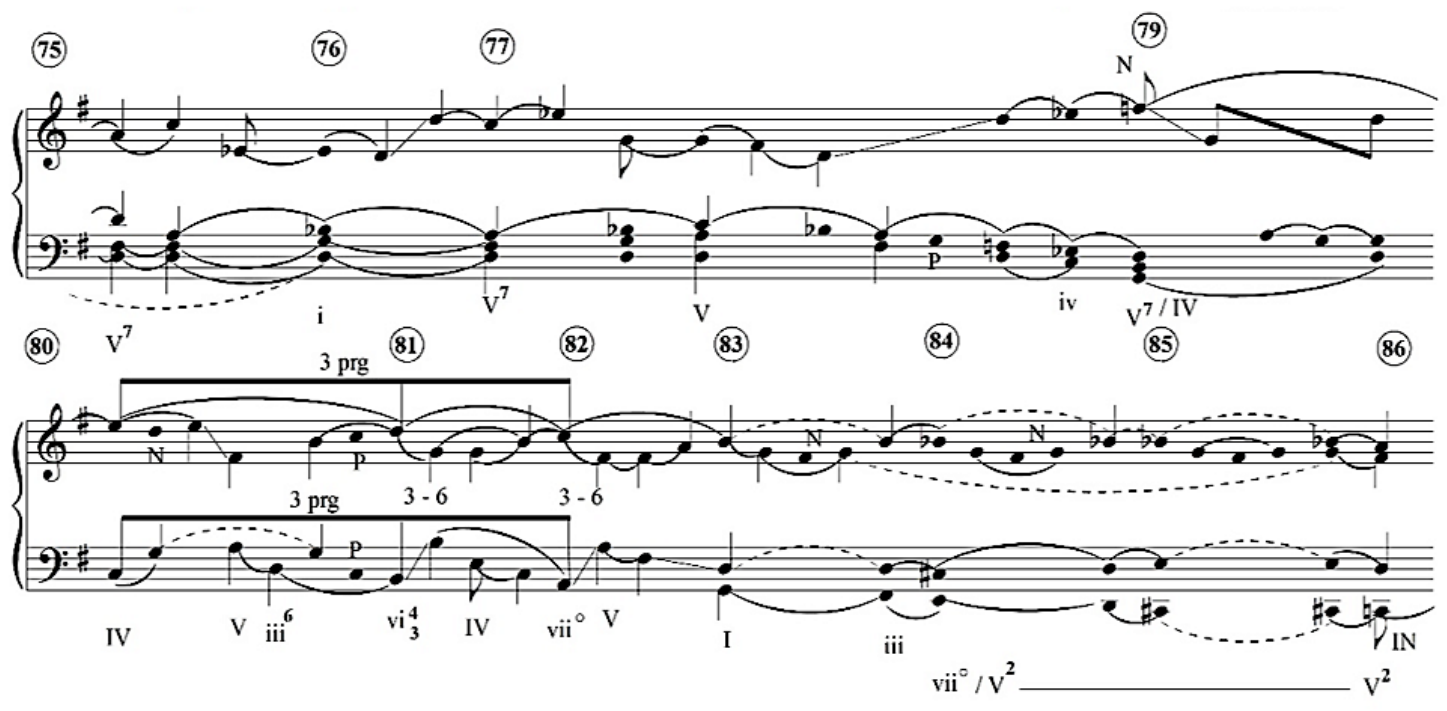

Fig. 10b - Representação da agógica e oscilações da dinâmica (compassos 83-86) por Perahia.

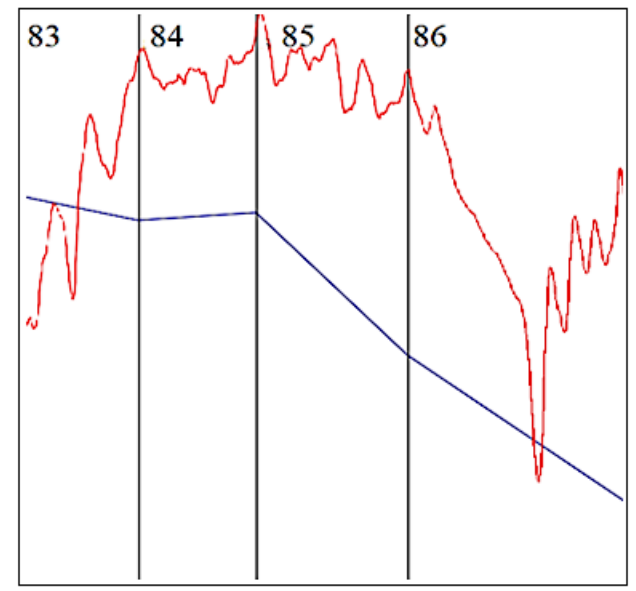

Fig.10c - Representação da agógica e oscilações da dinâmica (compassos 83-86) por Schiff.

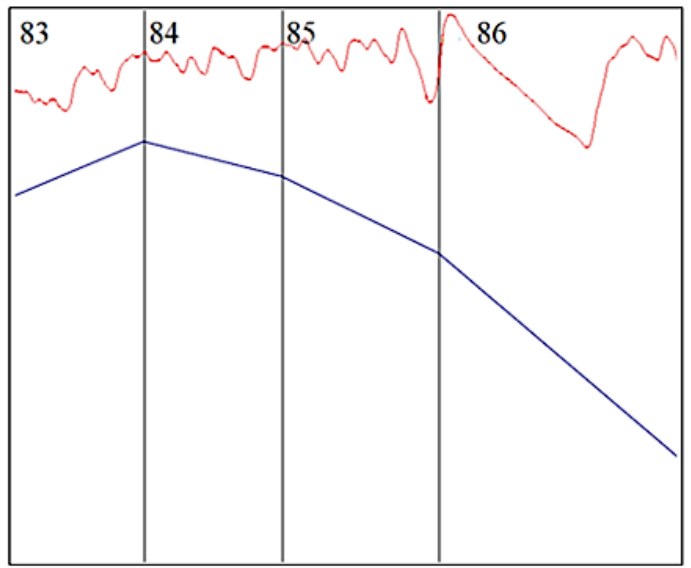


Fig. 10d - Representação da agógica e oscilações da dinâmica (compassos 83-86) por Arrau.

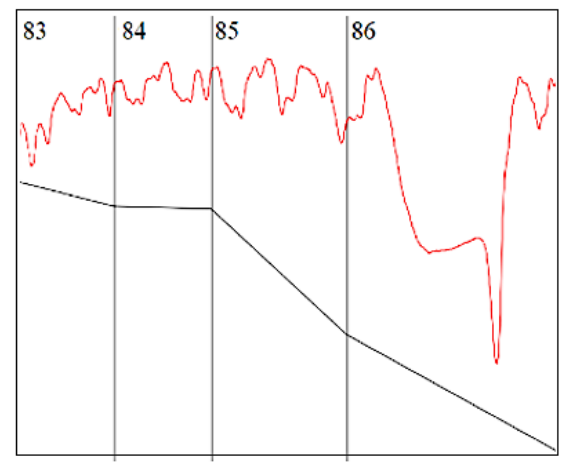

Fonte: Elaboração das autoras.

Outro acorde de importância estrutural inserido em trecho cadencial também é revelado no compasso 88. A percepção da interlocução entre vozes condutoras e aspectos expressivos permite notar a relação entre a cadência autêntica perfeita (compassos 87-88) e estratégia empregada pelos performers, a saber, o acelerando em direção a este importante ponto de chegada (compasso 88) e o objetivo harmônico, coincidente com a inauguração de uma coda (compassos 88-95). Nos exemplos da Figura 11, todos os performers empregam esta estratégia, além do declínio da dinâmica em direção ao compasso 88 .

Apesar das oscilações de dinâmica que acompanham a coda, percebe-se nas gravações uma dinâmica crescente em direção ao compasso 92, coincidente com acorde dissonante, resolvido no compasso seguinte. Tal resolução é acompanhada nas três gravações pelo decréscimo da dinâmica. O que se segue a esta resolução é uma proposta de modelagem da dinâmica e da agógica - observar o ritardando do compasso 93 - que reforça a sensação de encerramento desta composição. Uma percepção da interlocução entre as vozes condutoras e os aspectos expressivos nos permite notar no compasso 94 a dinâmica decrescente e o ritardando, que acompanham a descida final da Urlinie. A sensação de concretude é então reforçada pela proposta de modelagem oferecida pelos diferentes performers. A seguir, apresentamos nossa proposta de representação das vozes condutoras (plano frontal) e de sua interlocução com os aspectos expressivos que marcam os compassos finais deste prelúdio. 
Fig. 11 - Vozes condutoras e representação dos aspectos expressivos (compassos 87-95).

Fig. 11a - Vozes condutoras (plano frontal).

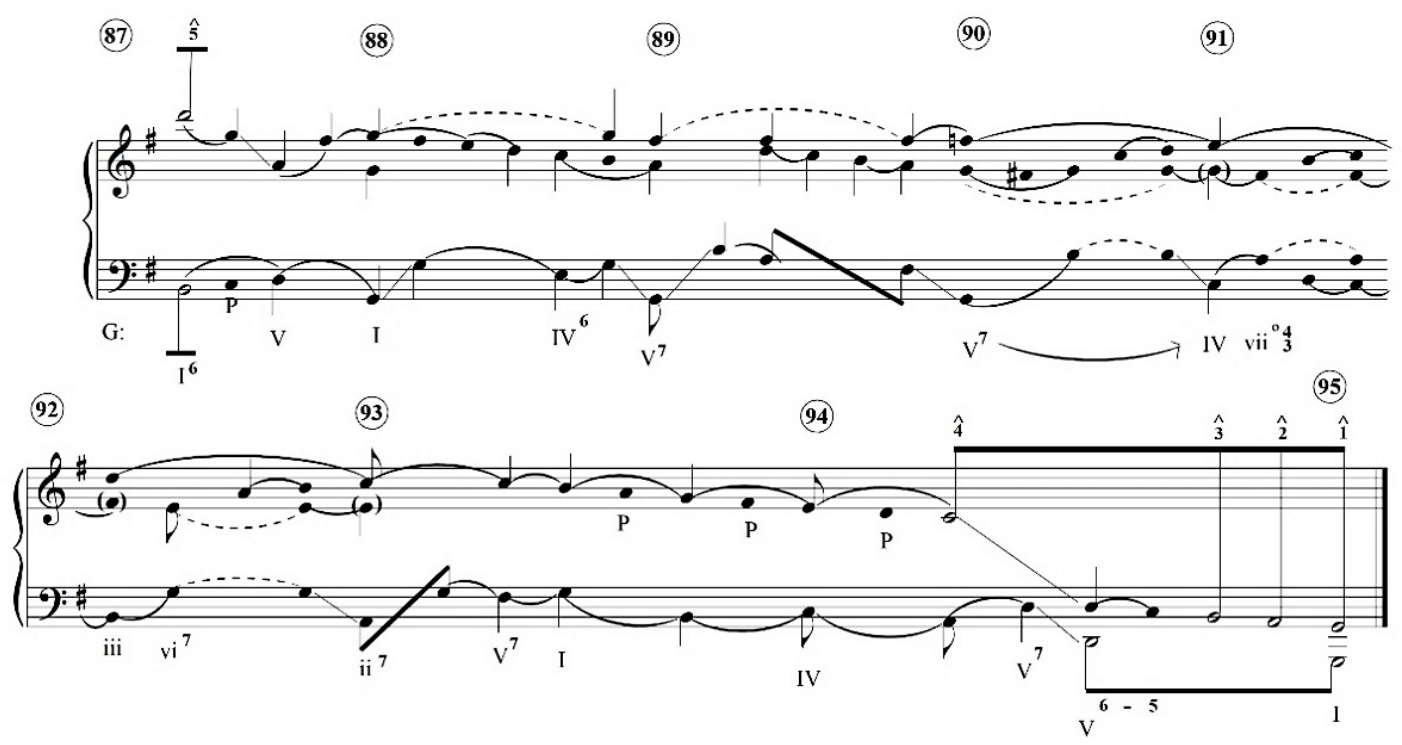

Fig. 11b - Representação da agógica e oscilações de dinâmica a partir da gravação de Perahia.

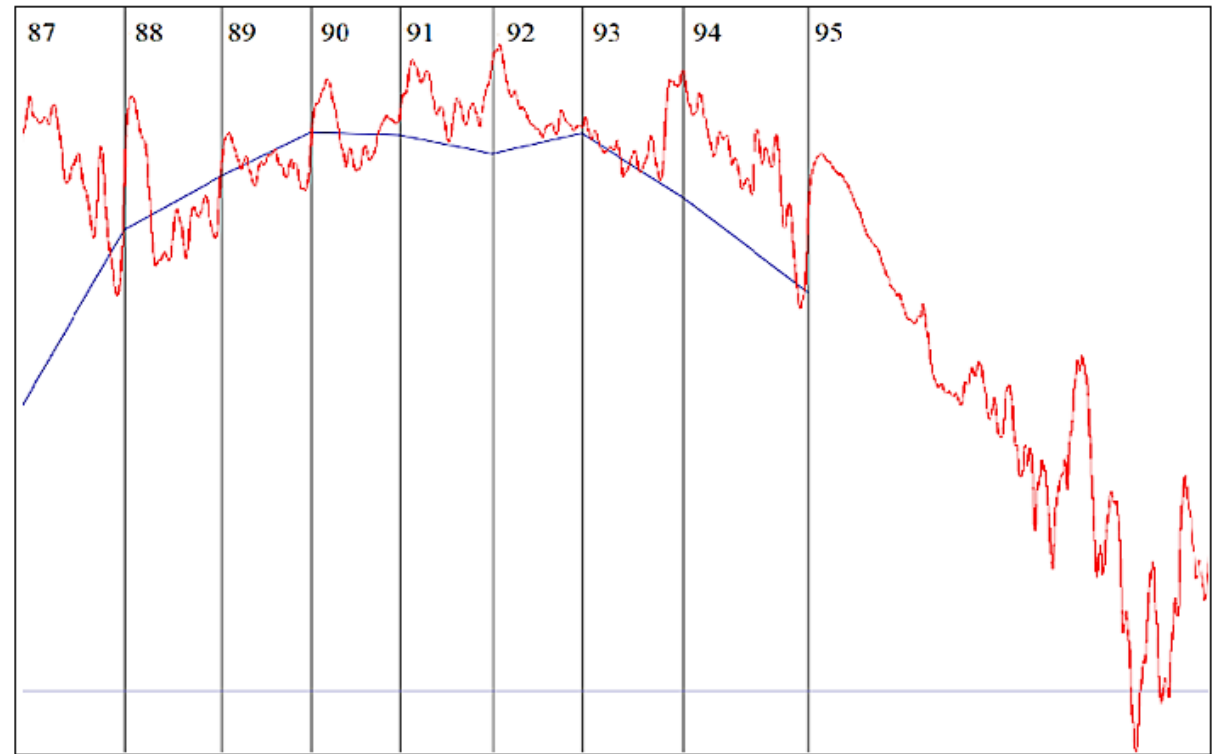


Fig. 11c - Representação da agógica e oscilações de dinâmica a partir da gravação de Schiff.

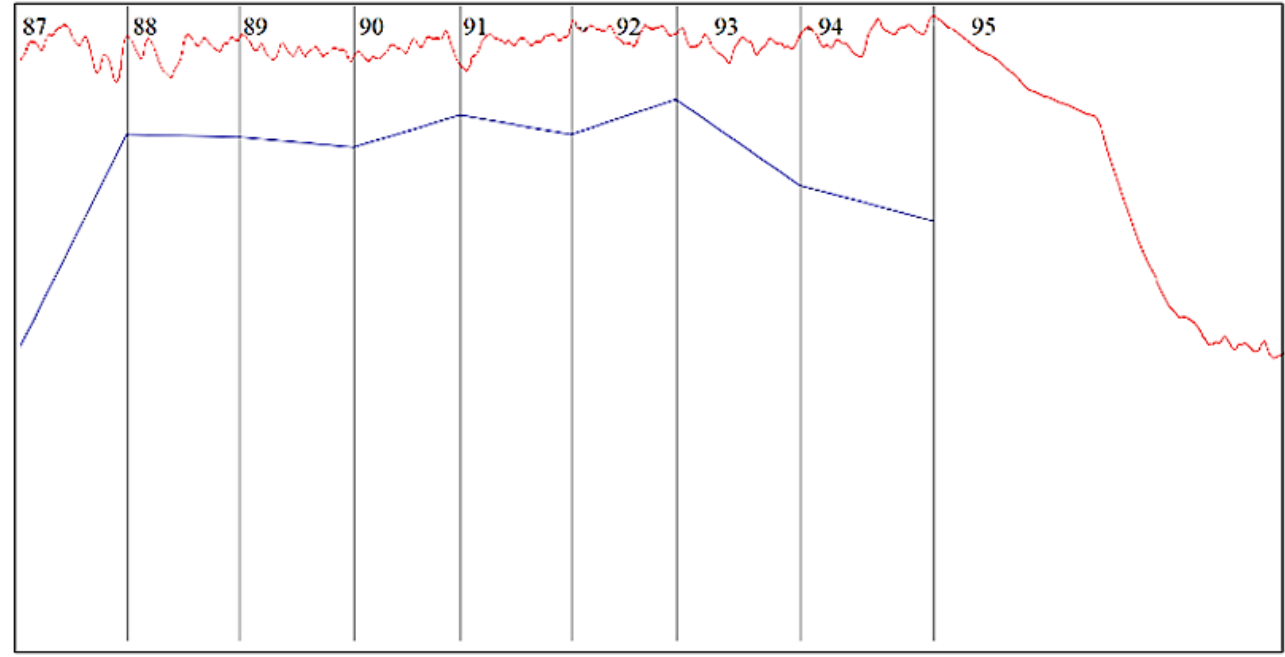

Fig. 11d - Representação da agógica e oscilações de dinâmica a partir da gravação de Arrau.

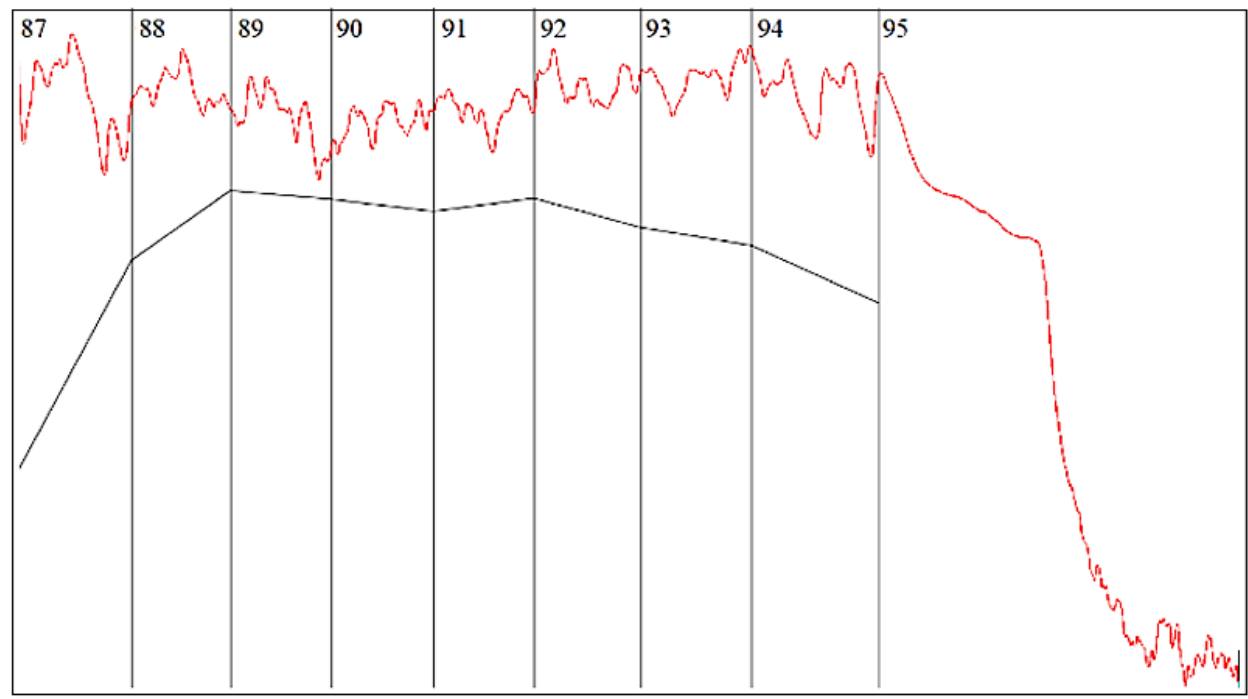

Fonte: Elaboração das autoras. 


\section{Considerações Finais}

O presente estudo não teve por objetivo oferecer uma abordagem exaustiva da estrutura que compõe o Praeambulum da Partita n. 5, de Bach. Tampouco teve o propósito de oferecer prescrições aos performers que remetessem às abordagens estruturalistas em Performance Musical. Antes, assumindo uma postura flexível frente ao estruturalismo buscou-se colaborar à discussão crítica acerca do papel da performance (e/ou das gravações) nas abordagens analíticas com propósito de embasar a prática performativa.

Com base numa consciência histórica acerca do desenvolvimento das principais linhas investigativas e problemáticas enfrentadas pela subárea Análise e Performance Musical, nos propusemos a demonstrar o potencial de colaboração de diferentes procedimentos analíticos para certos desafios performáticos. A escolha da obra analisada ocorreu em função de sua natureza notacional, caracterizada pela ausência de indicações quanto à realização de diferentes aspectos (dinâmica, articulação e o andamento), colocando assim uma série de desafios vinculados à modelagem expressiva. Buscamos oferecer na análise apresentada uma possibilidade de interlocução entre as atividades da análise e da performance musical, distanciando-se assim do autoritarismo que influenciou a postura de teóricos estruturalistas, marcado pela desvalorização das contribuições de performers (ou de suas gravações) aos achados analíticos.

Contudo, a crítica a essa postura autoritária, não correspondeu à desvalorização do potencial do conhecimento da estrutura para a abordagem dos desafios supracitados. Tampouco à desvalorização da análise a priori e da possibilidade de contribuição de método sistemático. Por assim entender, demonstramos o potencial da ferramenta analítica de Schenker na abordagem de diferentes desafios da modelagem expressiva, e também na produção de metáforas afetivas. Além disso, reconhecemos seu papel complementar na interpretação da forma musical, entendido como outro possível desafio a ser considerado por um performer (âmbito interpretativo da performance musical). 
Mostramos como a observação das vozes condutoras - e de sua interlocução com os eventos harmônicos - pode servir como embasamento à seleção de estratégias de execução. Em outras palavras, mostramos casos em que o reconhecimento de ponto de chegada do movimento linear se mostrou relevante para o estabelecimento de estratégia de dinâmica e de agógica. Vimos também como os conhecimentos de ordem estrutural não originados de uma abordagem rigorosa também podem se mostrar relevantes a uma escolha interpretativa, tais como o reconhecimento de cadências, pontos culminantes e finalizações de frases musicais. Assim, a análise a priori da estrutura se mostrou uma ferramenta interpretativa que colaborou com um refinamento das escolhas interpretativas.

Ademais, ilustramos procedimento nem sempre considerado pelas propostas estruturalistas em Performance Musical: o "caminho da performance à análise" ou o reconhecimento da colaboração de performers, por meio de suas estratégias interpretativas, para a análise musical. Buscamos neste artigo retratar uma possibilidade de "processo simbiótico" entre as atividades da análise e da performance, contribuindo assim para um redimensionamento do papel da performance (e também das gravações) nas abordagens analíticas.

Este redimensionamento pôde ser ilustrado a partir das contribuições de performers renomados, como Murray Perahia, András Schiff e Claudio Arrau, cujas performances colaboraram para a compreensão de aspectos métricos e de vozes condutoras. Sendo assim, atentamos ao potencial da chamada "análise da performance" à abordagem de questões relacionadas aos agrupamentos de eventos, favorecidas igualmente por conhecimentos teórico-musicais. Vimos também como tal proposta analítica cooperou igualmente à percepção e à representação de eventos lineares.

A tentativa para redimensionar as noções de performance (ou as decisões de realização de performers advindas das gravações) e de análise musical também se fez presente nas representações analíticas. Se durante décadas testemunhamos o peso excessivo conferido à análise da estrutura no conhecimento analítico, nossa proposta buscou ressaltar a importância de outros conhecimentos igualmente relevantes e integrantes do processo de escuta. Isto ocorreu por meio da incorporação de indicações de dinâmica e agógica nos gráficos de vozes condutoras e das representações analíticas ilustrativas da inter-relação entre vozes condutoras e aspectos expressivos (gráficos 
representativos da agógica e oscilações de dinâmica). Buscamos, portanto, conferir tratamento igualitário a diferentes possibilidades de conhecimentos analíticos. Assim, nossa proposta buscou oferecer uma resposta à reivindicação de especialistas que clamaram por uma abordagem metodológica mais abrangente nas pesquisas analíticas interessadas em contribuir com alguns dos desafios da performance musical (ROTHSTEIN, 1995; LESTER, 1995; RINK, 2002).

Desse modo, procuramos oferecer, ainda que de maneira muito breve, uma possibilidade de compreensão analítica mais abrangente em relação à ampla gama de conhecimentos analíticos com potencial de colaborar aos desafios da performance musical. Em outras palavras, buscamos oferecer uma possibilidade de compreensão musical aberta ao "processo simbiótico" entre as atividades da análise e da performance a fim de contribuir ao desenvolvimento de abordagens mais sensíveis e relevantes aos interesses de performers e à compreensão da obra como uma arte da performance musical. 


\section{Referências}

ABBATE, Carolyn. Music - Drastic or Gnostic? Critical Inquiry, v. 30. n.3, p. 505-536, 2004. Disponível em: https://www.journals.uchicago.edu/doi/pdfplus/10.1086/421160. Acesso em 5 de maio 2020.

ARRAU, Claudio. The Final Sessions - Volume 4. Compositor: Johann Sebastian Bach. Piano: Claudio Arrau. Switzerland: Philips, 1991.

BACH, Johann Sebastian. Partitas 4-6. Teclado. Kassel: Bärenreiter, 1976 [1731]. Disponível em: https://imslp.hk/files/imglnks/euimg/b/b3/IMSLP83650-PMLP03276-Partitas_No._4-6_-_ B\%C3\%A4renreiter.pdf. Acesso em: 15 out. 2019.

BACH, Johann Sebastian. Tocatta em Ré menor (BWV913). Teclado. Leipzig: Breitkopf und Härtel, 1890 [1708]. Disponível em: https://ks.imslp.info/files/imglnks/usimg/7/7f/IMSLP0320 3-Bach_-_BGA_-_BWV_913.pdf. Acesso em 15 out. 2019.

BADURA-SKODA, Paul. Dynamics. In: BADURA-SKODA, Paul. Interpreting Bach at the Keyboard. Oxford: Oxford University Press, 2002. p. 130-143.

BENT, Ian D.; POPLE, Anthony. Analysis. In: SADIE, Stanley (Ed.). The New Grove Dictionary of Music and Musicians, v. 1. London: Macmillan, 2001. p. 526-589.

BERRY, Wallace. Musical Structure and Performance. New Haven: Yale University Press, 1989.

BODKY, Erwin. Dynamic Problems. In: BODKY, Erwin. The Interpretation of Bach's Keyboard Works. London: Oxford University Press, 1960. p. 89-99.

BOWEN, José Antônio. Tempo, Duration, and Flexibility: Techniques in the Analysis of Performance. Musicological Research, v. 16, p. 111-156, 1996.

BOWEN, José Antônio. Finding the Music in Musicology: Performance History and Musical Works. In: COOK, Nicholas; EVERIST, Mark. Rethinking Music. Oxford: Oxford University Press, 2001.

CORREIA, Renata Coutinho de Barros. Análise e Performance: perspectivas de pesquisa, influências mútuas e abordagem crítica. 516 p. (Tese) Doutorado - Escola de Comunicações e Artes da Universidade de São Paulo, São Paulo, 2021.

BURKHART, Charles. Schenker's Theory of Levels and Musical Performance. In: BEACH, David (ed.). Aspects of Schenkerian Theory. New Haven: Yale University Press, 1983. p. 95-112.

BURKHART, Charles. Mid-bar Downbeat in Bach's Keyboard Music. Journal of Music Theory Pedagogy, v. 8, p. 3-26, 1994.

CADWALLADER, Allen; GAGNÉ, Clayton. Analysis of Tonal Music: A Schenkerian Approach [3. ed.].Oxford: Oxford University Press, 2011.

CONE, Edward T. Musical Form and Musical Performance. New York: Norton,1968.

COOK, Nicholas. Words About Music, or Analysis Versus Performance. In: COOK, Nicholas; JOHNSON, Peter; ZENDER, Hans. Theory onto practice: Composition, Performance and the Listening Experience. Leuven: Leuven University Press, 1999. p. 9-52. 
COOK, Nicholas. Beyond the Score: music as performance. New York: Oxford University Press, 2013.

CORREIA, Renata Coutinho de Barros; SILVA, Jéssica Evelyn Papi. Simbiose entre performance e análise musical: uma perspectiva analítica de vozes condutoras e análise da performance do Praeambulum da Partita n. 5 para teclas, de J. S. Bach (BWV 829). In: ENCONTRO INTERNACIONAL DE TEORIA E ANÁLISE MUSICAL, 5., 2019, Campinas. Anais... Campinas, Universidade Estadual de Campinas, 2019. p. 53-71. Disponível em: https://eitam5.nics.unicamp.br/wp-content/uploads/2020/12/EITAM5paper 05 CorreiaR SilvaJ-pp 053-071.pdf. Acesso em: 14 maio 2021.

FINANE, Ben. Heinrich Schenker, and the importance of Rubato. Listen: Life with Music \& Culture, 2019. Disponível em: https://www.steinway.com/news/features/the-humanist-murrayperahia. Acesso em: 15 de out. 2019.

FORTE, Allen; GILBERT, Steven E. Melodic Diminutions. In: FORTE, Allen; GILBERT, Steven. Introduction to Schenkerian Analysis. New York: W. W. Norton and Company, 1982. p. $8-82$.

FRAGA, Orlando. Progressão linear: uma breve introdução à teoria de Schenker. Curitiba: DeArtes, UFPR, 2009.

GABRIELSSON, Alf. 1860-1960. In: STANLEY, Sadie (Ed.). The New Grove Dictionary of Music and Musicians, v. 20. 2. ed. London: Macmillan, 2001. p. 528-530.

GEIRINGER, Karl. Obras para Teclado Solo. In: GEIRINGER, Karl. Johann Sebastian Bach: o apogeu de uma era. Rio de Janeiro: Jorge Zahar, 1985. p. 255-295.

GERLING, Cristina Capparelli; BARROS, Guilherme Sauerbronn de. Glossário de termos schenkerianos. Salvador: Tema, 2020.

GERLING, Cristina Capparelli; SOUZA, Jusamara. A performance como objeto de investigação. In: SEMINÁRIO NACIONAL DE PESQUISA EM PERFORMANCE MUSICAL, 1., 2000, Belo Horizonte. Anais... Belo Horizonte: UFMG, 2000. p. 114-125.

HAYLOCK, Julian. [Texto do encarte]. In: Murray Perahia - Bach Partitas 1,5 \& 6. Berlin: Sony Music Entertainment, 2009. 1 compact disc.

HOOD, Alison. Interpreting Chopin: Analysis and Performance. New York: Routledge, 2014.

KOCHEVITSKY, George A. Performing Bach's Keyboard Music: Dynamics A Postscript. The Journal of the Riemenschneider Bach Institute, v. 7, n. 1, p. 3-11,1976.

LARSON, Steve. On Analysis and Performance: The contribution of Durational Reduction to the Performance of J. S. Bach' s Two-part Invention in C major. Theory Only, v. 7, n. 1, p. 31-45, 1983.

LATARTARA, John; GARDINER, Michael. Analysis, Performance, and Images of Musical Sound: Surfaces, Cyclical Relationships and the Musical Work. Current Musicology, n. 84, p. 5378, 2007. Disponível em: https://academiccommons.columbia.edu/doi/10.7916/D8V40SVW. Acesso em: 28 dez. 2019. 
LATHAM, Edward D. Analysis and Performance Studies. A Summary of Current Research. Zeitschrift der Gesellschaft für Musiktheorie, v. 2, n. 2, p. 157-162, 2005.

LEECH-WILKINSON, Daniel. The Changing Sound of Music: Approaches to Studying Recorded Musical Performance. Londres: CHARM, 2009. Disponível em: http:www.charm. kcl.ac.uk/studies/chapters/intro.html. Acesso em 15 out. 2019.

LESTER, Joel. Performance and Analysis: interaction and interpretation. In: RINK, John (Org.). The practice of performance: studies in musical interpretation. Cambridge: Cambridge University Press, 1995. p. 197-216.

MATSCHULAT, Josias. Uma comparação entre as duas gravações do Cravo bem temperado de J. S. Bach por Andràs Schiff. Tese (Doutorado em Música) - Instituto de Artes, Universidade Federal do Rio Grande do Sul, Porto Alegre, 2015.

MCCLELLAND, Ryan. Performance and Analysis Studies: An Overview and Bibliography. Indiana Theory Review, v. 24, p. 95-106, 2003. Disponível em: https//www.jstor.org/sta ble/24046462. Acesso em: 10 jul. 2018.

NARMOUR, Eugene. On the Relationship of Analytical Theory to Performance and Interpretation. In: NARMOUR, Eugene; SOLIE, Ruth A. (Org.). Explorations in Music, the Arts, and Ideas: Essays in Honor of Leonard B. Meyer. New York: Pendragon Press, 1998. p. 317-340.

PALMER, Caroline. Music Performance. Annual Review of Psychology, v. 48, n. 1, p. 115-138, 1997. Disponível em: https://www.annualreviews.org/doi/pdf/10.1146/annureev.psych.48.1.115. Acesso em: 22 jul. 2020.

PERAHIA, Murray. Partitas 1, $5 \&$ 6. Compositor: Johann Sebastian Bach. Piano: Murray Perahia. Berlin: Sony Music Entertainment, 2009. 1 compact disc.

QUANTZ, Johann Joachim. Of the Duties that All Accompanying Instrumentalists in General Must Observe. In: QUANTZ, Johann Joachim. On Playing the Flute. Traduzido por Edward R. Reilly. New York: Schirmer Books, 1975. p. 266-294.

REPP, Bruno H. Expressive Timing in a Debussy Prelude: A Comparison of Student and Expert Pianists. Musicae Scientiae, v. 1, n. 2, 1997, p. 257-268.

RINK, John. Review of Musical Structure and Performance by Wallace Berry. Music Analysis, n. 9, p. 319-39, 1990. Disponível em: https://www.jstor.org/stable/853982. Acesso em: 11 de jul. 2018.

RINK, John. Authentic Chopin: History, Analysis and Intuition in Performance. In: RINK, John; SAMSON, Jim (Eds.). Chopin Studies 2. Cambridge: Cambridge University Press, 1994. p. 241244.

RINK, John. Playing in time: rhythm, meter in Brahms's Fantasie Op. 116. In: RINK, John (Ed.). The practice of performance: Studies in Musical Interpretation. New York: Cambridge University Press, 1995. p. 254-282.

RINK, John. Analysis and (or?) performance. In: RINK, John (Org.). Musical Performance: A Guide to Understanding. Cambridge: Cambridge University Press, 2002. p. 35-58. 
ROTHSTEIN, William. Analysis and the act of performance. In: RINK, John (Org.). The Practice of Performance: Studies in Musical Interpretation. Cambridge: Cambridge University Press, 1995. p. 217-240.

SCHENKER, Heinrich. Der Tonwille: Pamphlets/Quartely Publication in Witness of the Immutable Laws of Music, Offered to a New Generation of Youth. v. 1, n. 1-5. Editado por William Drabkin. Tradução de Ian Bent et. al. New York: Oxford University Press, 2004 [19211923].

SCHENKER, Heinrich. Der Tonwille: Pamphlets/Quartely Publication in Witness of the Immutable Laws of Music, Offered to a New Generation of Youth. v. 2, n. 6-10. Editado por William Drabkin. Tradução de Ian Bent et. al. New York: Oxford University Press, 2005 [19231924].

SCHIFF, András. Chromatic Fantasy and Fugue, Partita in G Major, English Suite in F Major. Compositor: Johann Sebastian Bach. Piano: András Schiff. Hungary: Hungaroton Classic, 1987. Disponível em: https://www.youtube.com/watch?v=HYrVDGtAZ2U. Acesso em: 10 jul. 2018.

SCHMALFELDT, Janet. On the Relation of Analysis to Performance: Beethoven's Bagatelles Op. 126, Nos. 2 and 6. Journal of Music Theory, v. 29, p. 1-31, 1985.

SCHMALFELDT, Janet. On performance, analysis and Schubert. Per Musi, v. 5/6, p. 38-54, 2002.

SONIC VISUALISER. Disponível em: <http://www.sonicvisualiser.org>. Acesso em: 15 de out. 2019.

SWINKIN, Jeffrey. Schenkerian Analysis, Metaphor, and Performance. College Music Symposium, v. 47, p. 76-99, 2007. Disponível em: <http://www.jstor.org/stable/40374506>. Acesso em: 5 jul. 2017.

SWINKIN, Jeffrey. Performative Analysis: Reimagining Music Theory for Performance. New York: University of Rochester Press, 2016.

TONG, Chee Yee Jennifer. Separate Discourses: a Study of Performance and Analysis. 1994. Tese (Doctor of Philosophy) - Faculty of Arts, University of Southampton, Southampton, 1994. 